\title{
LA PARTICIPACIÓN DE LA NOBLEZA EN EL GOBIERNO DE LAS CIUDADES EUROPEAS BAJOMEDIEVALES. ANÁLISIS COMPARATIVO
}

\author{
THE PARTICIPATION OF THE NOBILITY \\ IN THE GOVERNMENT OF THE EUROPEAN TOWNS \\ DURING THE LATE MIDDLE AGES. \\ A COMPARATIVE STUDY
}

Resumen: En las ciudades de la Europa occidental durante el período bajomedieval la presencia de miembros de la nobleza en los órganos de gobierno local fue un fenómeno poco frecuente, que sólo se constata a gran escala en unos pocos ámbitos, de entre los que cabe destacar dos: la Corona de Castilla e Italia. En este artículo el autor da cuenta de las principales manifestaciones del control político ejercido por la nobleza sobre los órganos de gobierno de las ciudades castellanas. Y presta atención a las importantes diferencias que a este respecto se dieron en los siglos bajomedievales entre estas ciudades y las de otros reinos europeos occidentales, donde la nobleza no participó en los órganos de gobierno urbano. Propone para ello ejemplos tomados de los reinos de la Corona de Aragón, el Imperio alemán, Francia e Inglaterra, dejando fuera de consideración el caso de las "repúblicas urbanas" italianas por su especificidad, derivada de su elevado grado de autonomía.

Palabras clave: Ciudades; Gobierno urbano; Nobleza urbana; Europa; Siglos XIV y XV.

\author{
MÁXIMO Diago HeRnANDO \\ Instituto de Historia, CSIC. Madrid
}

\begin{abstract}
In the western European towns the presence of members of the nobility in their institutions of local government was not a very widespread phenomenon during the Late Middle Ages. It can only be perceived in a great scale in very few regions, mainly in the kingdom of Castile and in Italy. In this article the author gives account of the main signs of the political control that the nobility exercised over the institutions of local government in the Castilian towns. He then pays attention to the important differences that in this respect existed during the Late Middle Ages between these towns and those of other kingdoms of western Europe, where the nobility didn't participate in the institutions of local government. He proposes some exemples taken from the kingdoms of the Crown of Aragon, the German Empire, France and England, leaving out of his consideration the case of the urban republics in Italy because of their specifical character, derived from their important degree of autonomy.
\end{abstract}

Key words: Towns; Urban government; Urban nobility; Europe; 14th and 15th centuries. 


\section{SUMARIO}

I. Los reinos hispánicos: contrastes entre la Corona de Castilla y la Corona de Aragón: 1. Miembros de la alta nobleza en el control de los oficios de la justicia de las grandes ciudades castellanas. Alcaldías y alguacilazgos mayores. 2. La tenencia de fortalezas realengas como plataforma para la participación en la vida política urbana de miembros de la alta nobleza. 3 . El oficio de "guarda mayor", una peculiaridad institucional de las ciudades de Cuenca, Huete y Alarcón. 4. Los miembros de la alta nobleza como regidores. 5. Miembros de la alta nobleza como procuradores a Cortes. 6. Participación de la nobleza en las instituciones de gobierno de las ciudades de la Corona de Aragón. 7. Principado de Cataluña. 8. Reino de Aragón. 9 Reino de Valencia.- II. La nobleza en el gobierno de las ciudades del Imperio Alemán: 1. Decadencia y desaparición de la nobleza urbana en el Imperio durante el período bajomedieval.- III. La nobleza urbana en el reino de Francia.- IV. El caso de Inglaterra.

Desde ciertas posiciones historiográficas se ha tendido a considerar nobleza y ciudades como dos realidades contrapuestas e incluso antagónicas, identificando a la primera con el mundo feudal, esencialmente rural, y a las segundas con las fuerzas renovadoras, de inspiración burguesa, que a largo plazo terminaron propiciando la implantación del régimen liberal-capitalista, en unos ámbitos ciertamente en fechas mucho más tempranas que en otros. Desde esta perspectiva no se concibe, por tanto, que los nobles pudiesen formar parte de los grupos gobernantes de las ciudades, salvo por imposición de instancias de gobierno superiores, en concreto emperadores, reyes o príncipes.

De hecho no fue así, sino que el estudio particularizado de las formas de gobierno vigentes en las ciudades europeas durante los períodos medieval y moderno, hasta la introducción de los regímenes liberales, demuestra que en algunas de ellas los nobles tomaron parte activa en las instituciones de gobierno y administración local, cuando no las tuvieron sometidas a un absoluto control, que conllevaba la exclusión de la participación en el ejercicio del poder del resto de los grupos sociales urbanos. Desde este punto de vista, sin embargo, las ciudades europeas ofrecieron un panorama enormemente diversificado, y por ello no cabe hacer valoraciones de carácter general sobre el papel que las mismas reservaron en sus estructuras políticas a la nobleza, puesto que éste fue muy diferente de unas a otras. A grandes rasgos en cada uno de los distintos reinos se adoptó un modelo peculiar, si bien es cierto que con frecuencia dentro de un mismo reino también se pueden advertir importantes contrastes de unas ciudades a otras, que, no obstante, no ponen en cuestión la tendencia general dominante.

Así trataremos de ponerlo de manifiesto en el presente trabajo, en el que nos hemos propuesto realizar un breve estudio de carácter comparativo de las estructuras político-institucionales de las ciudades europeas durante el período bajomedieval, desde la perspectiva concreta del papel que en las mismas se reservó a los miembros del estamento noble. No es nuestra intención, sin embargo, llevar a cabo un análisis de carácter exhaustivo, tomando en consideración todos y cada uno de los territorios del complejo continente europeo, ni siquiera de todos los de su sector occidental, sino que por el contrario, para simplificar la tarea, hemos optado por centrarnos en dar 
cuenta de unos pocos casos que consideramos suficientemente significativos, para demostrar la existencia de importantes contrastes entre los diferentes modelos de organización política de las ciudades que coexistieron en el continente durante el período medieval. Así, comenzaremos dando cuenta de la situación en la Península Ibérica, llamando la atención sobre el importante contraste que se dio entre las ciudades de la Corona de Castilla, por un lado, y las de los reinos de la Corona de Aragón, por otro. A continuación prestaremos atención al Imperio al norte de los Alpes, ámbito en el que, si bien en un primer momento sí alcanzó cierto desarrollo la nobleza urbana, en contra de lo mantenido por la historiografía clásica, poco a poco este grupo fue perdiendo relevancia en el transcurso de los siglos medievales, hasta terminar desapareciendo de prácticamente todas las ciudades donde tuvo en algún momento presencia significativa. Y, por fin, nos ocuparemos brevemente de los casos de los reinos de Francia e Inglaterra, donde la presencia de nobles en los órganos de gobierno de las ciudades fue un fenómeno marginal. Fuera de nuestra consideración en el presente trabajo dejaremos, sin embargo, a las ciudades italianas, que ofrecen una problemática singular porque disfrutaron de un margen de autonomía sin parangón en otros territorios europeos, incluido el Imperio al norte de los Alpes, y además lograron dominar extensos espacios territoriales en los que previamente habían proliferado los señoríos nobiliarios.

\section{LOS REINOS HISPANOS: \\ CONTRASTES ENTRE LA CORONA DE CASTILLA Y LA CORONA DE ARAGÓN}

Desde el punto de vista del papel reservado en las estructuras sociopolíticas urbanas a la nobleza, los reinos hispánicos no presentaron en el período bajomedieval un panorama homogéneo, sino que por el contrario se advierten importantes contrastes entre unos y otros que no pueden ser pasados por alto, a pesar de que algunos autores, en su afán por encontrar rasgos comunes a todos los regímenes de gobierno urbano vigentes en la Península e incluso en Europa occidental en su conjunto, han tendido a resaltar más los parecidos que las diferencias, insistiendo en destacar que a fin de cuentas todos eran "oligárquicos" y favorecían la consolidación de "patriciados" 1 .

Sin cuestionar la validez de la tesis de que en todas las ciudades peninsulares de cierto tamaño se impuso en el período bajomedieval una

\footnotetext{
${ }^{1}$ Entre otros autores que han insistido en resaltar el común carácter oligárquico de los regímenes de gobierno de las ciudades de los reinos hispanos bajomedievales, sin conceder gran importancia a las diferencias existentes en la composicion de los grupos oligárquicos urbanos en los distintos reinos, cabe mencionar. Josep FERNÁNDEZ I TRABAL, La oligarquía urbana catalana en el tránsito de la Edad Media a la Moderna 1480-1516. Una síntesis interpretativa en Ernest BELENGUER CEBRIA, "De la unión de coronas al Imperio de Carlos V" Madrid, 2001, pp. 299328. Enric GUINOT RODRÍGUEZ, La baja Edad Media en los siglos XIV-XV. Economía y Sociedad, Editorial Síntesis, Madrid, 2003. Y José María MONSALVO ANTÓN, La Baja Edad Media en los siglos XIV-XV. Política y cultura, Editorial Síntesis, Madrid, 2000.
} 
tendencia hacia la consolidación de formas de gobierno oligárquico, no podemos, sin embargo, dejar de resaltar al mismo tiempo el hecho de que el perfil sociopolítico de los grupos gobernantes en dichas ciudades varió de forma notable de unos reinos a otros. Desde este punto de vista la Corona de Castilla ofrece una fuerte singularidad, tanto en el panorama hispano, en particular, como en el del conjunto de la Europa occidental, en general, por la fuerte impronta nobiliaria de las estructuras sociopolíticas de sus grandes núcleos urbanos, a la que sólo resulta posible encontrar paralelo en el período medieval en Italia, donde, no obstante, las ciudades, por el elevado grado de autonomía del que llegaron a disfrutar, presentaban unas características muy diferentes a las de las castellanas, plenamente integradas en un Estado monárquico cada vez más centralizado que dejaba escaso margen para el autogobierno urbano.

En las ciudades castellanas de los siglos XIV, XV y XVI los miembros del estamento noble no sólo fueron admitidos al desempeño de oficios en las instituciones de gobierno local, sino que en la mayoría de ellas lograron que se les reservasen los de mayor rango, y que, en contrapartida, fuesen los ciudadanos pecheros los excluidos de su desempeño. Pero, al hablar de la nobleza en la Corona de Castilla, no hemos de perder de vista el hecho de que se trataba de un grupo muy numeroso, pues en ningún otro territorio europeo, con la única excepción significativa de Polonia, la población noble llegó a representar un porcentaje tan elevado del total de la población ${ }^{2}$. Como consecuencia de ser tan numeroso, el estamento noble fue también en Castilla excepcionalmente diverso en su composición, al integrar familias con perfiles socioeconómicos muy dispares, entre las que abundaban incluso las que vivían en condiciones de pobreza. Y es precisamente esta diversidad que caracteriza al estamento noble castellano la que ha llevado a autores como Adeline Rucquoi a explicar la falta de un ideal "burgués" en la sociedad castellana de fines del Medievo como resultado de que en este reino prevaleció entonces un concepto de nobleza distinto al dominante en el resto de Europa, por considerarse allí noble a quien ejercía el poder, y tenía riquezas ${ }^{3}$.

La posición hegemónica que, tanto en el plano político como en el social y cultural ${ }^{4}$, alcanzó la nobleza en las ciudades castellanas bajomedievales entendemos, no obstante, que no se puede explicar exclusivamente como consecuencia de que prevaleciese en este reino un concepto de nobleza más abierto que el que se impuso en otros reinos europeos. Ciertamente hubo nobles en determinadas ciudades castellanas, de las que Burgos nos ofrece un ejemplo paradigmático, que presentaban un perfil muy parecido al de los patricios de muchas ciudades europeas, que en sus respectivos reinos eran

${ }^{2}$ Vid. M.C. GERBET, La noblesse dans le royaume de Castille. Étude sur ses structures sociales en Estrémadure (1454-1510), Paris, 1979.

${ }^{3}$ Adeline RUCQUOI, Las oligarquías urbanas y las primeras burguesías en Castilla, en "El tratado de Tordesillas y su época", Valladolid, 1995, vol. I, pp. 345-70.

${ }^{4}$ Sobre la impronta nobiliaria de la cultura en las ciudades castellanas bajomedievales reflexiona Angus MACKAY, Cultura urbana y oligarcas sevillanos en el siglo xv, en "Actas del I Congreso de Historia de Ảndalucía. Andalucía Medieval”, II, Córdoba, 1978, pp. 163-171. 
radicalmente excluidos de las corporaciones nobiliarias. Pero no constituyeron éstos el elemento dominante en los grupos oligárquicos castellanos, en los que abundaron mucho más en términos relativos los individuos que eran señores de vasallos, grandes propietarios de tierras, profesionales de la milicia y servidores de la monarquía en tareas políticas y diplomáticas.

Además, una peculiaridad castellana sobre la que conviene insistir radica en que no es sólo que sus ciudades estuviesen gobernadas por oligarquías constituidas por personas a las que se reconocía la condición noble, sino que muchos de los principales oficios de gobierno en las mismas fueron controlados por miembros de la alta nobleza, grupo sociopolítico que tenía las principales bases de su poder fuera de dichas ciudades, en sus grandes estados señoriales. Algunos autores, para referirse a las intervenciones de miembros de la alta nobleza en la vida política de las ciudades castellanas durante el siglo XV y las primeras décadas del siglo XVI, han utilizado la expresión de "injerencias bastardas" estaban basadas en procedimientos ilegítimos, no previstos en el orden institucional vigente. Pero lo cierto es que, en un importante número de ciudades, en el propio orden institucional sí se contemplaba la participación de los grandes señores de vasallos en la vida política ciudadana, puesto que se les reservaba el desempeño de algunos de los principales oficios de gobierno local.

Por supuesto, esta situación no se dio de forma generalizada, y alcanzó mucho más desarrollo en las ciudades de la mitad meridional del reino que en las de la mitad septentrional. En algunos ámbitos incluso las ciudades, en su afán por evitar que los miembros de la alta nobleza se inmiscuyesen en su vida política interna, lograron en época de los Reyes Católicos que se les prohibiese a éstos fijar su residencia en ellas, como ocurrió, por ejemplo, en la Rioja, donde ciudades como Santo Domingo de La Calzada o Logroño se resistieron con éxito a que los grandes señores de vasallos de la región se avecindasen o comprasen casas en el interior de su recinto amurallado ${ }^{6}$.

El control por miembros de la alta nobleza de oficios de gobierno local fue, sin embargo, una práctica muy extendida en las ciudades realengas castellanas de los siglos XV y XVI, para la que resulta difícil encontrar paralelos en otros ámbitos de la Europa occidental. Y por ello vamos a continuación a centrarnos en poner de manifiesto este singular fenómeno,

${ }^{5}$ J.M $^{\mathrm{a}}$. MONSALvo ANTÓ́N, La sociedad política en los concejos castellanos de la Meseta durante la época del regimiento medieval. La distribución social del poder, en Concejos y ciudades en la Edad Media hispánica, "II Congreso de Estudios Medievales", Fundación Sánchez Albornoz, Madrid 1990, pp. 392 y ss. I IDEM, Parentesco y sistema concejil. Observaciones sobre la funcionalidad politica de los linajes urbanos en Castilla y León (Siglos XIII-XV), "Hispania", 185 (1993), p. 962.

${ }^{6}$ Vid. Máximo Diago Hernando, Santo Domingo de la Calzada en la Baja Edad Media. Aspectos de su organización político-institucional, "Berceo", 130 (1996), pp . 107-122. Y Francisco Javier GOICOLEA JULIÁN, El gobierno urbano en la rioja en la época medieval e inicios de la Edad Moderna (s. XIII-mediados del XVI), Instituto de Estudios Riojanos, Logroño, 2004, pp. 97 y ss. Sobre las relaciones políticas entre los linajes de alta nobleza y las ciudades riojanas Vid. Máximo DIAGO HERNANDO, El poder de la nobleza en los ámbitos regionales de la Corona de Castilla a fines del Medievo: Las estrategias politicas de los grandes linajes en la Rioja hasta la revuelta comunera, "Hispania", 223 (2006), pp. 501-546. 
dando cuenta con ejemplos concretos de la gran gama de oficios que representantes de este grupo sociopolítico, considerado extraño al sistema político urbano ${ }^{7}$, llegaron a desempeñar en esta época en las ciudades más importantes de Castilla.

\section{Miembros de la alta nobleza en el control de los oficios de la justicia de las grandes ciudades castellanas: alcaldías y alguacilazgos mayores}

Comenzaremos para ello refiriéndonos a los oficios de la justicia, dando cuenta del caso verdaderamente singular de Guadalajara, ciudad que pese a pertenecer al realengo y figurar en el privilegiado grupo de las diecisiete que en el siglo XV mantuvieron el derecho a enviar procuradores a Cortes, estaba gobernada por unos oficiales de la justicia, en concreto alcaldes y alguacil, que no eran nombrados por el rey ni por los representantes de la sociedad política local, sino por uno de los miembros más influyentes de la alta nobleza castellana, el marqués de Santillana, y más tarde duque del Infantado, del linaje Mendoza, a quien correspondió por privilegio la designación de dichos oficiales, que le aseguraba el ejercicio de una extraordinaria influencia sobre la vida política local, hasta el año 1543, cuando finalmente fue introducido el corregimiento en la capital alcarreña ${ }^{8}$.

Fuera de Guadalajara, también en otras muchas importantes ciudades de la mitad meridional de la Corona de Castilla fue habitual que representantes de la más alta nobleza ocupasen oficios de la justicia como eran las alcaldías mayores o el alguacilazgo mayor, los cuales llegaron a controlar de forma vitalicia, e incluso en ocasiones transmitir en herencia a sus hijos. Un buen ejemplo lo encontramos en Córdoba, donde llegó a haber dos alcaldías mayores, una de las cuales estuvo gran parte de la segunda mitad del siglo XV en poder de la poderosa familia de los Fernández de Córdoba, señores de Aguilar, gracias a lo cual Alonso Fernández de Córdoba, señor de Aguilar, logró mantener sometida a la ciudad a un férrea tiranía entre los años 1464 y 1477. Por su parte, otro importante oficio de la justicia, el del alguacilazgo mayor, estuvo durante mucho tiempo controlado en esta misma capital andaluza por miembros de otra rama del prolífico linaje de los Fernández de Córdoba, la de los condes de Cabra, señores de Baena. Y, aunque ciertamente, tras la consolidación en el trono de los Reyes Católicos, la regularización del envío de corregidores terminó por dejar vaciado de contenido político el

\footnotetext{
${ }^{7} \mathrm{La}$ idea de que los miembros de la alta nobleza terratenientes no pueden ser considerados en sentido estricto miembros de una oligarquía urbana es defendida por Yolanda GUERRERO NAVARRETE y José María SÁnCHEZ BENITO, Cuenca en la Baja Edad Media: Un sistema de poder, Cuenca, 1994, p. 139.

${ }^{8}$ Vid. Francisco LAYNA SERRANO Historia de Guadalajara y sus Mendozas en los siglos XV y XVI, Madrid, 1942, t. II, p. 338. Y José Miguel LÓPEZ VILLALBA, Concejo abierto, regimiento y corregimiento en Guadalajara (1346-1546), "Espacio, Tiempo y Forma. Historia Medieval", 5 (1992), p. 76.
} 
desempeño de estos oficios de la justicia ${ }^{9}$, no por ello sus titulares renunciaron a los mismos, sino que los mantuvieron bajo su control, e incluso trataron de revitalizarlos cuando se dieron las circunstancias favorables. Así lo demuestran muy en particular las actuaciones del marqués de Priego en los años que siguieron a la muerte de la reina Isabel la Católica, cuando tanto él como el conde de Cabra llegaron a hacerse con el control de las varas de la justicia en un momento de vacío de poder, en que no había corregidor en la ciudad, y más adelante el referido marqués desafió abiertamente la autoridad del rey Fernando el Católico, que se vio obligado a enviar una expedición armada para reducirlo a la obediencia ${ }^{10}$. El caso del marqués de Priego resulta, por otra parte, remarcable debido a que este poderoso señor de vasallos no sólo fue alcalde mayor de la ciudad de Córdoba, sino que también desempeñó este mismo oficio en la ciudad de Antequera, según nos testimonia un curioso documento del año 1503, que recoge el nombramiento por los Reyes Católicos del bachiller Escalante como corregidor de esta ciudad andaluza, realizado en respuesta a una solicitud presentada por el propio marqués ${ }^{11}$.

Una situación bastante similar a la de Córdoba constatamos en época bajomedieval en Toledo y Sevilla, donde también los oficios de alcaldías y alguacilazgos mayores fueron de nombramiento regio, $\mathrm{y}$ fueron ocupados habitualmente por representantes de los más poderosos linajes de alta nobleza del entorno de dichas ciudades. Así, en Toledo la alcaldía mayor llegó a perpetuarse en el transcurso del siglo XV a lo largo de cuatro generaciones en el seno del poderoso linaje de los Ayala, condes de Fuensalida, que encabezaron uno de los dos bandos nobiliarios que se disputaron el dominio de la ciudad durante toda esta centuria, hasta el año 1489, fecha en que, tras la muerte del segundo conde de Fuensalida, los Reyes Católicos hicieron merced del oficio a su contador Don Gutierre de Cárdenas, comendador mayor de León $^{12}$. Por su parte el oficio de alguacil mayor de Toledo también fue desempeñado en el siglo XV por destacados miembros de la alta nobleza castellana, como, por ejemplo, el conde de Alba, García Álvarez de Toledo, de quien lo adquirió por compra Alfonso de Silva, entrando así a formar parte del patrimonio de los condes de Fuensalida, que se lo transmitieron de padres

\footnotetext{
${ }^{9}$ Margarita CABRERA SÁNCHEZ, Nobleza, oligarquía y poder en Córdoba al final de la Edad Media Universidad Córdoba, $1998, \mathrm{pp}, 90-4$. Vid. también EADEM, Los corregidores de Córdoba en el siglo XV, "Meridies", 2 (1995), pp. 95-108.

${ }^{10}$ Vid. John EDWARDS, La révolte du marquis de Priego à Cordove, "Mélanges de la Casa de Velázquez", 12 (1976), pp. 165-72; IDEM, Christian Córdoba. The city and its region in the late Middle Ages, Cambridge University Press, 1982 , pp. 155 y ss.

${ }^{11}$ AGS, RGS, VI-1503, fol. 43.

${ }^{12}$ Vid. Juan Ramón PALENCIA HERREJÓN, Los Ayala de Toledo: Desarrollo e instrumentos de poder de un linaje nobiliario en el siglo XV., Diputación Provincial, Toledo, 1995. "Se trata de la "alcaldía mayor de la justicia", por debajo de la cual existía otra alcaldía mayor "ordinaria", que fue desempeñada por miembros del linaje Carrillo. Cfr. p. 36.
} 
a hijos durante el siglo XVI, después de haber perdido el control sobre la alcaldía mayor ${ }^{13}$.

En Sevilla, por su parte, las alcaldías y alguacilazgos mayores estuvieron vinculados en el siglo XV a los linajes más poderosos de la nobleza de la región como fueron los Guzmán, condes de Niebla, los Ponce de León, los Estúñiga, condes de Ledesma, y los Portocarrero de Moguer ${ }^{14}$. Y en época de los Reyes Católicos dichos oficios, pese a la generalización del régimen de corregidores, continuaron asegurando a sus titulares una notable influencia en la vida política local, dado que en esta capital andaluza, al recurrir los reyes el envío de asistentes en lugar de corregidores, los alcaldes mayores y el alguacil mayor mantuvieron su derecho de asistir con voz y voto a las sesiones del cabildo, y otras muchas prerrogativas. Continuaron reclutándose además entonces entre los más poderosos linajes de la nobleza andaluza. Es el caso del duque de Medinasidonia, quien como alcalde mayor recibía una quitación anual de $28.000 \mathrm{mrs}$. con cargo a los bienes de propios de la ciudad ${ }^{15}$, y delegaba el desempeño del oficio en un lugarteniente letrado, quien por ello ingresaba la mitad de dicha cantidad ${ }^{16}$. También en esta época ocupó una alcaldía mayor Don Álvaro de Estúñiga, duque de Plasencia, en la que le sucedió en 1488 su nieto homónimo, hijo de su primogénito Pedro ${ }^{17}$.Y, en 1506, Fadrique Enríquez de Ribera, hijo del Adelantado mayor de Andalucía, accedió a ocupar otra por renuncia de Don Pedro de Guzmán ${ }^{18}$. Por su parte el oficio de alguacil mayor, que, al igual que los de alcalde mayor, confería a quien lo desempeñaba voz y voto en la reuniones del cabildo, estuvo

${ }^{13} \mathrm{Ibíd}$. pp. 107-8. Sobre la pervivencia de alcaldías y alguacilazgos mayores como oficios honoríficos en Toledo, tras la consolidación del régimen de corregidores, a partir del siglo XVI Vid. Francisco José ARANDA PÉREZ, Poder y poderes en la ciudad de Toledo: Gobierno, sociedad y oligarquías urbanas en la Edad Moderna, Ediciones de la Universidad de Castilla-La Mancha, Cuenca, 1999.

${ }^{14}$ Miguel Ángel LADERO QUESADA, Historia de Sevilla. La ciudad medieval, Sevilla, 1976, p. 137. Vid. también Deborah KIRSCHBERG SCHENCK y Marcos FERNÁNDEZ GÓMEZ, El concejo de Sevilla en la Edad Media (1248-1454). Organización Institucional y Fuentes Documentales, I, Sevilla, 2002, pp. 209-230.

${ }^{15}$ Juan de Mata CARriazo (Dir.), El Tumbo de los Reyes Católicos del concejo de Sevilla, vol. V, Sevilla, 1971, p. 102.

${ }^{16}$ Vid. Marcos FernÁndeZ, Pilar Ostos y Ma . Luisa PARdo, El Tumbo de los Reyes Católicos del concejo de Sevilla. IX. 1499-1501. Fundación Ramón Areces, Madrid, 2001, pp. 150-1. Provisión de 30-I-1500 al concejo de Sevilla para que se paguen al licenciado Manzanedo, teniente de alcalde mayor por el duque de Medinasidonia, $14.000 \mathrm{mrs}$. por cada año que ejerció el oficio.

${ }^{17}$ Juan de Mata CARRIAzo (Dir.), El Tumbo de los Reyes Católicos del concejo de Sevilla, vol. IV, Sevilla, 1968, pp. 281-2. Provisión de Salamanca, 20-XII-1488, por la que los reyes nombran a Alvaro de Estuñiga alcalde mayor por renuncia que en él efectuo su abuelo el duque de Plasencia, que era alcalde mayor "de una de las tres alcaldías mayores antiguas" de Sevilla. En 1506 el duque de Béjar seguía siendo alcalde mayor de Sevilla. Vid. Marcos FERNÁNDEZ y Pilar OSTOS, El Tumbo de los Reyes Católicos del concejo de Sevilla. XII (1503-1509), Fundación Ramón Areces, Madrid, 2004, pp. 464-5, Valladolid, 6-IV-1506.

${ }^{18}$ Marcos FERnÁNDEZ y Pilar Ostos, El Tumbo de los Reyes Católicos del concejo de Sevilla. XII (1503-1509), Fundación Ramón Areces, Madrid, 2004, pp. 447-8, Salamanca, 7-II-1506. 
desempeñado durante el reinado de los Reyes Católicos por miembros del linaje Guzmán, al que pertenecían los duques de Medinasidonia ${ }^{19}$.

En Jaén, por su parte, también existió durante el período bajomedieval un oficio de la justicia que fue temporalmente controlado por influyentes representantes de la alta nobleza regional. Se trata del de alguacil mayor, que fue ocupado desde el año 1460 por el Condestable Miguel Lucas de Iranzo, a quien a su muerte le sucedió en el desempeño del mismo su hijo Luis de Torres, que lo ejerció hasta el momento de hacerse fraile en 1499. Entonces los Reyes Católicos designaron como alguacil mayor a un noble cortesano, Antonio de Fonseca, contador mayor, señor de Coca y Alaejos, que no mantenía ningún tipo de vínculo de origen con la sociedad política jienense ${ }^{20}$, aunque ciertamente llegó a ser nombrado veinticuatro de esta capital andaluza, y a representarla como procurador en las Cortes de Valladolid de $1518^{21}$, al tiempo que logró reforzar su implantación política en Andalucía tras ser nombrado alcalde mayor de Écija en $1514^{22}$.

En otras ciudades andaluzas de menor rango se contempló igualmente la existencia de alcaldes mayores y alguacil mayor, que eran nombrados por el rey, conforme al modelo toledano. Y, aunque las informaciones de que disponemos sobre la identidad de las personas que desempeñaron estos oficios son de momento muy escasas, de nuevo nos encontramos con que hubo entre ellos miembros de la alta nobleza, aunque no procedían de los linajes más poderosos de Andalucía. Así, por poner un solo ejemplo, recordaremos que en Carmona, según nos informa el profesor González Jiménez, los alcaldes mayores fueron desde tiempos de Enrique II miembros del linaje de origen cordobés de los Sotomayor ${ }^{23}$, y un miembro de este linaje, Gómez Méndez de Sotomayor, era en 1475 alguacil mayor de esta villa, además de alcaide de sus alcázares y veinticuatro de la ciudad de Sevilla ${ }^{24}$.

\footnotetext{
${ }^{19}$ En 1482 fue nombrado alguacil mayor Esteban de Guzmán, en sustitución de su padre, Alvar Pérez de Guzmán, que acababa de fallecer. Juan de Mata CARRIAZO, (Dir.), El Tumbo de los Reyes Católicos del concejo de Sevilla, vol. İI, Sevilla, 1968, pp. 190-1, Medina del Campo, 16II-1482.

${ }^{20}$ Isabel RAMOS VÁZQUEZ, El concejo de Jaén (1474-1556), Universidad de Jaén, Jaén, 2002 , pp. $437-8$.

${ }^{21}$ Vid. José Manuel NIETO SORIA (Dir.), Orígenes de la monarquía hispánica. Propaganda y legitimación. (Ca. 1400-1520), Dykinson, Madrid, 1999, doc. no. 78, pp. 516-9. Se ha de recordar que en 1499 este mismo individuo había sido procurador a Cortes por la ciudad de Toro, de donde era originario.

${ }^{22}$ Vid. AGS, RGS, IV-1515. Sobrecarta de una provisión expedida en Segovia, 30-V-1514, por la que se hacía merced al contador mayor Antonio de Fonseca del oficio de alcalde mayor de Ecija, vacante por muerte del comendador Martín Fernández Galindo. La sobrecarta se da porque a raíz de haber presentado la provisión de nombramiento en el concejo de Ecija, algunos de los oficiales presentes la habían supliçado. Antonio de Fonseca, contador mayor y señor de Coca y Alaejos, recibió en 1518 privilegio del rey Carlos I para poder renunciar en sus hijos u otras personas los oficios que entonces acumulaba de regidor de Toro, veinticuatro y alguacil mayor de Jaén y alcalde mayor de Ecija. AGS, RGS, III-1518-10.

${ }^{23}$ Manuel GonZÁLEZ JIMÉNEZ, El concejo de Carmona a fines de la Edad Media (1464-1523), Sevilla, 1973 , pp. 153 y 157.

${ }^{24}$ Vid. Juan de Mata CARRIAZO (Dir.) El Tumbo de los Reyes Católicos del concejo de Sevilla. I (Años 1474-1477), Sevilla, 1929-1968, pp. 181-3, Valladolid, 30-XI-1475.
} 
Fuera de la ciudad de Toledo, y de las ciudades andaluzas que fueron repobladas a fuero toledano, la presencia de miembros de la alta nobleza en el desempeño de oficios de la justicia alcanzó menor difusión, aunque también se dieron algunos casos que conviene recordar, para completar el panorama. Así, en primer lugar, cabe recordar que en Valladolid el oficio de merino mayor, equivalente a grandes rasgos al de alguacil mayor, que era también de nombramiento regio, fue desempeñado durante el siglo XV por miembros del linaje de los Niño, condes de Buelna ${ }^{25}$. Este mismo oficio de merino mayor también existió en la ciudad de Burgos, pero, a diferencia de Valladolid, no tuvo carácter vitalicio, sino que por el contrario las personas que lo desempeñaron se renovaron con inusitada frecuencia, y no pudo por ello quedar adscrito a ningún linaje en particular. Los merinos mayores de Burgos de los que tenemos noticia fueron en su mayoría individuos que no formaban parte de la sociedad política burgalesa. Y de nuevo entre ellos nos encontramos con miembros de los linajes de alta nobleza, como Íñigo Ortiz de Zúñiga, que lo fue en 1453, y el conde de Alba, que ejerció el cargo en 1456. Pero en términos porcentuales éstos no fueron mayoritarios ${ }^{26}$. Por su parte, la constitución política burgalesa también contempló la figura de los alcaldes mayores, que persistieron en el desempeño de sus funciones incluso cuando se regularizó el envío de corregidores durante el reinado de los Reyes Católicos. Pero, a juzgar por los datos de que disponemos, no hubo apenas miembros de la alta nobleza que accediesen al desempeño de este oficio, que tenía carácter vitalicio, como el de regidor ${ }^{27}$.

Conocidos miembros de la alta nobleza castellana también llegaron a controlar los oficios de la justicia en determinadas ciudades castellanas gracias a haber sido nombrados por el rey como "justicias mayores". Se ha de puntualizar, sin embargo, que en este caso nos encontramos ante oficios que no eran propiamente municipales, sino que se desempeñaban por delegación del rey, y que conllevaban, por tanto, la suspensión en sus funciones de los oficiales de la justicia ordinarios ${ }^{28}$. La práctica de designar justicias de fuera, que sustituyesen temporalmente a los alcaldes ordinarios puestos por las sociedades políticas locales, fue inaugurada por Alfonso X, y retomada después por Sancho IV, Alfonso XI, Pedro I y los distintos monarcas de la dinastía Trastamara, quienes recurrieron a la misma de forma más o menos esporádica. La falta de documentación y de trabajos de investigación dedicados al análisis de esta cuestión nos impiden, sin embargo, determinar

\footnotetext{
${ }^{25}$ El recibimiento de Pero Niño como merino de Valladolid en 1498 en Fernando PINO REBOLLEDO, Libro de actas del ayuntamiento de Valladolid. Año 1498, Valladolid, 1992, p. 129. El recibimiento del "sotamerino" en p. 138.

${ }^{26}$ Vid. Yolanda GUERRERO NAVARRETE, Organización y gobierno en Burgos durante el reinado de Enrique IV de Castilla (1453-1476), Madrid, 1986, pp. 422-33.

${ }^{27}$ Para más detalles sobre las atribuciones e identidad de los alcaldes mayores burgaleses Vid. Yolanda GUERRERO NAVARRETE, Organización y gobierno en Burgos...

${ }^{28}$ Sobre la distinción entre oficios reales y oficios municipales Vid. José María GARCíA MARTín, El oficio público en Castilla durante la Baja Edad Media, Universidad, Sevilla, 1974. Conviene precisar, no obstante, que la distinción no siempre resulta clara en la práctica.
} 
la frecuencia con que estos justicias de fuera fueron enviados a las distintas ciudades castellanas, y la identidad de las personas que desempeñaron el cargo. A título ilustrativo interesa hacer constar, no obstante, que en el período Trastamara entre los designados como tales justicias hubo destacados representantes de la alta nobleza, como Pedro Fernández de Velasco, que era justicia mayor de Soria en 1374, o Juan de Luna, pariente del Condestable Don Álvaro, que lo fue de esta misma ciudad por merced que le hizo Juan II en $1445^{29}$. Y la relación de miembros de la alta nobleza que con la denominación de corregidores estuvieron al frente del gobierno de ciudades castellanas a lo largo del siglo XV, y muy en particular a partir de la consolidación en el trono de los Reyes Católicos, es mucho más larga, si bien aquí no vamos a entrar ni siquiera a esbozarla, por tratarse de un cargo con un claro carácter de funcionario delegado del rey, desempeñado por personas que no podía estar integradas en la correspondiente sociedad política urbana, sino que obligatoriamente debían ser extrañas a la misma, es decir, forasteras.

Por esta misma razón, tampoco vamos a profundizar en la identificación de los miembros de la alta nobleza que estuvieron temporalmente al frente del gobierno de algunas ciudades castellanas en calidad de "gobernadores", puesto que de nuevo se trata de un oficio de carácter extraordinario, que no estaba previsto en las constituciones políticas urbanas ${ }^{30}$. Pero, en contrapartida, sí nos vamos a ocupar brevemente de dar cuenta de la utilización de la tenencia de fortalezas realengas por miembros de la alta nobleza como plataforma para participar en la vida política de determinadas ciudades, en las que se les reconoció a los tenentes de tales fortalezas el derecho a participar regularmente en las asambleas concejiles ${ }^{31}$.

\section{La tenencia de fortalezas realengas como plataforma para la participa- ción en la vida política urbana de miembros de la alta nobleza}

Desde este punto de vista un ejemplo paradigmático nos lo proporciona la ciudad de Sevilla, donde el duque de Medinasidonia, además de ejercer el oficio de alcalde mayor, recibió de los Reyes Católicos en 1475 la merced

\footnotetext{
${ }^{29}$ Máximo DiAgo HeRnANDo, Estructuras de poder en Soria a fines de la Edad Media, Junta de Castilla y León, Valladolid, 19393, p. 73.

${ }^{30}$ Como ejemplo ilustrativo podemos citar el caso de Pedro López de Ayala, que fue nombrado por Enrique IV, el 4-VII-1468, gobernador de la ciudad de Toledo, convirtiéndose gracias a ello en un auténtico lugarteniente dê rey en la ciudad. Vid. Juan Ramón PALENCIA HERREJÓN, op. cit., pp. 110-1. Por su parte en Valladolid en 1464 el almirante Fadrique Enríquez intentó conseguir la guarda y gobierno de la ciudad, aunque sin éxito. Vid. Adeline RUCQUOI, Valladolid en la Edad Media, Junta de Castilla y Leon, Valladolid, 1987, Vol. II, pp. 54 y ss. Un caso bastante más tardío de concesión del título de gobernador de una ciudad realenga a un miembro de la alta nobleza lo encontramos en la merced que en 1508 hizo Fernando el Católico al Gran Capitán de la alcaidía y cargo de gobernador de Loja. Vid. A. MALPICA CUELLO, Análisis de un "conflicto social": la oposición al Gran Capitán en el reino de Granada, en "Estudios sobre Historia de España. Homenaje a Manuel Tunón de Lara", Madrid, 1981, t. I, pp. 123-132.

${ }^{31}$ Consideraciones sobre el papel desempeñado por las fortalezas realengas en las ciudades castellanas del Bajo Medievo en Máximo DIAGO HERNANDO, El papel de los castillos en las ciudades de señorio regio en Castilla y en el Imperio alemán. Análisis comparativo. Siglos XII$X V$, "Estudios de Historia y Arqueología Medievales", 11 (1996), pp. 85-129.
} 
de la tenencia de las atarazanas y alcázares de la ciudad, con el privilegio adicional de que los dos alcaides que designase para estar al cargo en su nombre de las dichas atarazanas y alcázares pudiesen entrar a las reuniones del cabildo hispalense con voz y voto, y percibir las mismas remuneraciones que los veinticuatros (regidores) de la ciudad ${ }^{32}$. Dos años después, en 1477, dicha tenencia escapó, sin embargo, al control de la poderosa casa de Medinasidonia, al ser concedida en merced por la reina Isabel la Católica a su secretario Francisco Ramírez de Madrid ${ }^{33}$. Y en adelante los tenentes ya únicamente tuvieron reconocido el derecho a una sola "voz y voto" en las reuniones del cabildo hispalense, aunque se les facultó para que pudiesen ejercerla a través de lugartenientes ${ }^{34}$.

Sin abandonar Andalucía, nos encontramos con que también en Carmona, según nos informa el profesor González Jiménez, los alcaides consiguieron participar regularmente en las reuniones del concejo entre 1476 y 1508, siguiendo el precedente sentado por Godoy, el alcaide puesto por Don Pedro Girón en 1465, quien consiguió consolidarse entonces como máxima autoridad en la ciudad ${ }^{35}$. En otros ámbitos de la Corona de Castilla no sabemos muy bien hasta qué punto estuvo extendida la costumbre de tolerar la entrada regular a las asambleas concejiles del tenente de la fortaleza realenga. Pero al menos disponemos de algunos testimonios de que así ocurrió en determinadas ciudades. Un ejemplo lo tenemos en Soria, donde el tenente Jorge de Beteta, miembro de una familia de la nobleza media originaria de Ciudad Real que terminó arraigando en la ciudad del Duero, reconoció que había acostumbrado asistir a las reuniones de ayuntamiento, antes de ser nombrado regidor en 1506 , en su condición de alcaide ${ }^{36}$.

Por otra parte, como prueba de la notable influencia que los tenentes de las fortalezas realengas llegaron a ejercer en la vida política interna de las ciudades donde las mismas se ubicaban, conviene recordar que Iñigo López de Mendoza, conde de Tendilla, nombrado tenente de la fortaleza de Granada tras su conquista a los nazaríes, representó como procurador a esta ciudad en

\footnotetext{
${ }^{32}$ Marcos Fernández, Pilar Ostos y Ma . Luisa PARdo, El Tumbo de los Reyes Católicos del concejo de Sevilla. VII. 1494-1497, Fundación Ramón Ảreces, Madrid, 1998, pp. 356-7, Palencia, 21-IX-1475.

${ }^{33}$ Juan de Mata CARRIAZo (Dir.), El Tumbo de los Reves Católicos del concejo de Sevilla vol. II, Sevilla, 1968, pp. 92-96, Sevilla, 10-IX-1477. Isabel la Católica ordena al duque de Medinasidonia que entregue la tenencia del alcázar y las atarazanas de Sevilla al secretario Francisco Ramírez de Madrid.

${ }^{34}$ Así en la merced que se hizo en 1495 a Don Álvaro de Portugal, presidente del Consejo, para que fuese alcaide de los alcázares y atarazanas de Sevilla, se incluyó también la concesión de "voz y voto de veinticuatro, con el salario acostumbrado". Vid. Marcos FERNÁNDEZ, Pilar OSTOS y $\mathrm{M}^{\mathrm{a}}$. Luisa PARDO, El Tumbo de los Reyes Católicos del concejo de Sevilla. VII. 1494 1497. Fundación Ramón Areces, Madrid, 1998 pp. 174-7. Madrid, 6-I-1495. En 1505 se facultó expresamente a Don Jorge de Portugal, que habia sucedido a su padre Don Alvaro en la referida tenencia, a que en su lugar pudiese entrar un lugarteniente a las sesiones del cabildo. Vid. Marcos FERNÁNDEZ, y Pilar OSTOS, El Tumbo de los Reyes Católicos del concejo de Sevilla. XII, 15031509, Fundación Ramón Areces, Madrid, 2004, pp. 321-2, Segovia 5-VII-1505.

${ }^{35}$ Manuel GONZÁLEZ JIMÉNEZ, op. cit., pp. 134-5 y 158-60.

${ }^{36}$ Vid. Máximo DiAGo HeRnANDO, Estructuras de poder, cit., p. 221.
} 
las Cortes de Madrid de 1510, mientras que un hijo suyo, Luis de Mendoza, lo hizo en las Cortes de Valladolid de 1506.

\section{El oficio de "guarda mayor": Una peculiaridad institucional de las ciudades de Cuenca, Huete y Alarcón}

En unas pocas ciudades de la submeseta sur los linajes de alta nobleza tuvieron a su disposición un oficio singular que les aseguró a quienes pudieron controlarlo la participación desde una posición preeminente en las instituciones de gobierno local. Nos referimos al de "guarda mayor", que está constatado desde finales del siglo XIV en las ciudades de Cuenca, Huete y Alarcón ${ }^{37}$. De estas tres cabe destacar a la primera por haber sido aquélla en que el oficio mejor sirvió a uno de los linajes de alta nobleza más poderosos de la región conquense como plataforma para desarrollar una intensa actividad política en el ámbito local. En efecto, a lo largo de varias generaciones, que cubren prácticamente todo el siglo XV y la primera mitad del siglo XVI, el oficio de guarda mayor de Cuenca fue ejercido por los señores de Cañete, del linaje Mendoza, convertidos después en marqueses de Cañete, quienes gracias al desempeño del mismo accedieron con regularidad a las reuniones del concejo con voz y voto.

No todos los autores que han analizado la evolución de las relaciones de poder en Cuenca durante el siglo XV han valorado del mismo modo el papel desempeñado por los guardas mayores del linaje Mendoza en la vida política local. Entre quienes más lo han infravalorado cabe destacar a José Antonio Jara, quien en su modelo prácticamente no tiene en cuenta la presencia en las instituciones de gobierno conquenses de miembros de la alta nobleza, señores de grandes estados, como eran los Mendoza, de la rama de los señores de Cañete ${ }^{38}$. Mucha más relevancia reconoce a la actividad politica desplegada por éste y otros linajes de alta nobleza en el escenario conquense durante el siglo XV y en los primeros años del siglo XVI la profesora Quintanilla Raso al dar cuenta de los enfrentamientos banderizos que allí se sucedieron durante este período ${ }^{39}$. Y nosotros por nuestra parte, centrándonos en las dos primeras décadas del siglo XVI, hemos podido demostrar que el guarda mayor Diego Hurtado de Mendoza, primer marqués de Cañete, fue una de las personalidades más influyentes desde el punto de vista político en Cuenca, que aspiró a hacerse con el control de los principales resortes de ejercicio del poder en la ciudad en el turbulento período que siguió a la muerte

\footnotetext{
${ }^{37}$ J.I. ORTEGA CERVIGÓN, El intrusismo nobiliario en los concejos castellanos: el oficio de guarda mayor de Cuenca durante el siglo XV en J.F. JIMÉNEZ ALCÁZAR, J. ORTUNO MOLINA Murcia, 2003, pp. 147-162. Y Máximo DIAGO HERNANDO, La alta nobleza en la vida política de las ciudades castellanas en las décadas precomuneras: el ejemplo de Cuenca (1506-1507), "Cuadernos de Historia Moderna", 15 (1994), pp. 121-41.

${ }^{38}$ José Antonio JARA FUENTE, Concejo, poder y élites. La clase dominante de Cuenca en el siglo XV, CSIC, Madrid, 2000.

${ }^{39} \mathrm{M}$ a C. QUINTANILla RASO, Política ciudadana y jerarquización del poder. Bandos y parcialidades en Cuenca, "En la España Medieval”, 20 (1997), pp. 219-250.
} 
de Isabel la Católica ${ }^{40}$. Y por este motivo despertó la animadversión de un importante sector de la sociedad política local, encabezado por varios regidores, que dio lugar al desencadenamiento de una enconada lucha de bandos que culminó en los años 1520 y 1521, cuando los seguidores de Diego Hurtado de Mendoza, que estaba ausente del reino, pues se había embarcado en La Coruña en compañía del rey Carlos, llegaron a verse forzados a abandonar la ciudad durante varios meses tras hacerse con el poder el bando rival, encabezado por Luis Carrillo de Albornoz, señor de Torralba y Beteta ${ }^{41}$.

También en la ciudad de Huete influyentes miembros de la alta nobleza desempeñaron durante el siglo XV el oficio de guarda mayor, que les aseguró una notable influencia sobre la vida política local, incrementada aún más por el hecho de que se trataba de un oficio vitalicio, mientras que los demás oficiales que participaban en las asambleas concejiles se renovaban todos los años ${ }^{42}$. Uno de los primeros guardas mayores de Huete fue Pedro Carrillo de Huete, halconero de Juan II y señor de Priego, que también desempeñó el oficio de alcalde mayor de las alzadas de la ciudad, y fue tenente de su fortaleza, por lo que llegó a ejercer un dominio casi absoluto sobre la misma ${ }^{43}$. Tras morir éste sin herederos el oficio de guarda mayor pasó al linaje de los Sandoval, señores de La Ventosa, quienes en el transcurso del reinado de Enrique IV fueron desplazados por Lope Vázquez de Acuña, que se hizo también con la tenencia de la fortaleza de la ciudad. Por haber militado éste, no obstante, en el bando contrario a los Reyes Católicos, que apoyaba la candidatura del rey de Portugal al trono castellano, estos monarcas lo destituyeron y Alejo de Sandoval pudo volver a desempeñar de nuevo el oficio, que permaneció en adelante en poder de su linaje a lo largo de varias generaciones ${ }^{4}$. Nos consta, sin embargo, que con el transcurso del tiempo ciertos sectores de la sociedad política local comenzaron a mostrar su disconformidad con la persistencia del oficio, que consideraban perjudicial para el buen gobierno de la ciudad, por el hecho de que se desempeñaba con carácter vitalicio, y por ello confería a su titular una influencia excesiva en la vida política local frente al resto de oficiales, que desempeñaban sus cargos con carácter anual. Por este motivo, en fecha no precisada, se tomó el acuerdo de iniciar pleito en nombre de la ciudad para que se suprimiese el oficio de guarda mayor, disponiéndose además que en adelante ningún regidor ni

\footnotetext{
${ }^{40}$ Vid. Máximo DiAgo HeRnANDo, La alta nobleza en la vida politica, cit.

${ }^{41}$ Vid. Máximo DiAGo HERNANDO, El conflicto de las Comunidades en Cuenca (1520-1522), "Chronica Nova", 29 (2002), pp 27-62.

${ }^{42}$ Vid. AGS, RGS, XII-1518. Provisión al corregidor de Huete. Hernando de Ribera, vecino de Huete, como uno del pueblo de "llanos", había informado que "en tiempos pasados algunos caballeros de la ciudad procuraron que hubiese un oficio que se llama guarda para que entrase en el ayuntamiento de concejo. El oficio se hubo con algunos favores, y cuando la ciudad vio que le era más dañoso que provechoso, y porque los oficios de la ciudad son anuales y el oficio de guarda es perpetuo, acordaron de hacer una ordenanza para que se siguiese pleito en nombre de la ciudad para que no hubiese la dicha guarda".

${ }^{43} \mathrm{Vid} . \mathrm{M}^{\mathrm{a}} \mathrm{C}$. QUINTANILLA RASO, Reflexiones sobre los intereses nobiliarios y la política regia en torno a Huete en el siglo XV, "Anuario de Estudios Medievales", 18 (1988), pp. 439-53.

${ }^{44}$ José María SÁNCHEZ BENITO, El poder en una pequeña ciudad castellana: el ejemplo de Huete en el siglo XV, "En la España Medieval", 25 (2002), pp. 184-5.
} 
ningún otro oficial del concejo fuese recibido si previamente no prestaba juramento de que se seguiría adelante con dicho pleito. A pesar de ello, sin embargo, a fines de 1518, un vecino de Huete llamado Hernando de Ribera, quien compareció en la Corte "como uno del pueblo de llanos", denunció que, por ser vitalicio el cargo de guardamayor, continuaba haciéndose en el ayuntamiento de concejo sólo lo que este oficial quería, y por ello el pleito no se seguía como debiera ${ }^{45}$. No hemos conseguido averiguar cómo se resolvió finalmente este litigio, pero en cualquier caso lo que nos interesa resaltar es que durante el siglo XV y las primeras décadas del siglo XVI el oficio de guardamayor proporcionó a diversos miembros de linajes nobles con implantación señorial en el ámbito conquense una magnífica plataforma para intervenir desde una posición dominante en la vida política de la ciudad de Huete, y que, aunque hubo intentos de privarles de dicha plataforma mediante la supresión del oficio, tropezaron con fuertes obstáculos para salir adelante.

Por fin, por lo que toca a Alarcón, disponemos de menos informaciones sobre la identidad de sus guardamayores, y sobre el papel que éstos desempeñaron en la vida política local. Sólo cabe destacar que en 1395 lo era Martín Ruiz de Alarcón, vasallo de Enrique III $^{46}$, miembro de un linaje de nobleza media que llegó a labrarse un importante patrimonio señorial en la región conquense a fines de la Edad Media ${ }^{47}$.

\section{Los miembros de la alta nobleza como regidores}

La presencia de miembros de linajes de la alta nobleza, muchos de ellos titulados, entre los regidores es un fenómeno que se dio, con diverso grado de intensidad, en el siglo XV y en las primeras décadas del siglo XVI en un gran número de ciudades castellanas, especialmente en las de mayor rango político y potencial demográfico. Ciñéndonos a las dieciocho que tuvieron representación en Cortes, podemos destacar entre las de la submeseta norte a la de Valladolid, donde tendieron a fijar su residencia en estos siglos varios de los más influyentes representantes de la alta nobleza del reino, aunque ciertamente sólo unos pocos de ellos consiguieron para sí mismos o para algunos de sus hijos el oficio de regidor. Es el caso del conde de Ribadeo, quien accedió al regimiento de esta ciudad en 1480, a la muerte de su hermano Sebastián ${ }^{48}$. Y, como ejemplo de segundón de un linaje de alta nobleza que también tuvo acceso al regimiento vallisoletano, cabe mencionar

\footnotetext{
${ }^{45}$ AGS, RGS, XII-1518. Comisión al corregidor de Huete, a petición de Hernando de Ribera, vecino de la ciudad.

${ }^{46}$ Vid. Miguel Lasso de LA Vega, El señorío de Valverde, Cuenca, 1945, doc. n ${ }^{\circ} .9$.

${ }^{47}$ Algunas referencias al ascenso de este linaje en Miguel RoDRíGUEZ LLOPIS, Procesos de movilidad social en la nobleza conquense: La Tierra de Alarcón en la Baja Edad Media, en Francisco GARCÍA GONZÁLEZ (Ed.) Tierra y familia en la España meridional, siglos XIII-XIX, Universidad de Murcia, Murcia, 1998, pp. 49 y ss.

${ }^{48}$ AGS, RGS, IV-1480, fol. 54.
} 
a Don Pedro Pimentel, que fue regidor hasta su muerte en 1504, cuando le sucedió en el cargo su hijo Bernardino Pimentel ${ }^{49}$.

Además de en Valladolid, también está constatada la presencia de nobles titulados en el regimiento en León, donde en 1512 fue nombrado regidor el conde de Luna, Francisco Fernández de Quiñones ${ }^{50}$, y en Zamora, donde el adelantado de Cazorla, miembro del prolífico y poderoso linaje de los Mendoza, recibió merced de un regimiento en $1493^{51}$.

Mucho más numerosos son, sin embargo, los ejemplos de regidores pertenecientes a linajes de alta nobleza que hemos logrado recopilar en las ciudades con voto en Cortes de la submeseta sur. Así, comenzando con Guadalajara, comprobamos que en esta ciudad el linaje Mendoza, además de controlar los oficios de la justicia, consiguió colocar a algunos de sus miembros más prominentes en el regimiento.

Fueron en concreto el conde de Tendilla, Iñigo López de Mendoza, que fue regidor hasta el año 1485 por el estado de los caballeros y escuderos ${ }^{52}$, y el conde de Coruña y vizconde de Torija, Bernardino Suárez de Mendoza, quien paradójicamente desempeñó este mismo oficio por el estamento de los pecheros, hasta que lo renunció en 1490 en un tal Diego Pérez ${ }^{53}$. Pero, pese a la evidente preferencia demostrada por los Mendoza hacia la ciudad de Guadalajara, no fue en ésta, sin embargo, en la única en que la que lograron hacerse un hueco en la principal institución de gobierno local gracias al desempeño del oficio de regidor, sino que también lo consiguieron en otras importantes ciudades realengas. Así, al caso ya aludido del adelantado de Cazorla, que fue regidor en Zamora, se ha de añadir el de un hijo del duque de Infantado, llamado Don Juan de Mendoza, quien fue nombrado regidor de Madrid en julio de 1488 por virtud de una renuncia que efectuó en él de su oficio su suegro Pedro Núñez de Toledo, señor de Cubas y de Griñón ${ }^{54}$.

Además de Guadalajara y Madrid, también la ciudad de Toledo hizo un hueco en su regimiento a miembros de destacados linajes de alta nobleza, como Juan de Tovar, hijo segundo del Condestable Íñigo Fernández de Velasco, quien fue nombrado regidor en 1522, para cubrir la vacante producida tras el ajusticiamiento en Villalar del capitán comunero Juan de Padilla $^{55}$, o Bernardino de Cárdenas, marqués de Elche, quien recibió merced

\footnotetext{
${ }^{49}$ AGS, RGS, III-1504. Nombramiento de Bernardino Pimentel como regidor de Valladolid para cubrir la vacante producida por la muerte de su padre, Don Pedro Pimentel.

${ }^{50} \mathrm{AGS}$, RGS, II-1512. Es nombrado por virtud de la renuncia que efectuó a su favor el regidor Hernando de San Andrés.

${ }^{51}$ Manuel Fernando LADERO QUESADA, La ciudad de Zamora en la época de los Reyes Católicos. Economía y gobierno, Zamora, 1991, p. 151.

${ }^{52}$ AGS, RGS, XII-1485, fol. 30.

${ }^{53}$ AGS, RGS, I-1490, fol. 15.

${ }^{54}$ AGS, RGS, VII-1488, fol. 303.

${ }^{55} \mathrm{El}$ nombramiento de Juan de Tovar como regidor de Toledo en AGS, RGS, V-1522.
} 
de este oficio en este mismo año por renuncia a su favor de Juan Carrillo ${ }^{56}$. Por su parte, también disponemos de referencias indirectas de la concesión en 1517 al marqués de Villena de un regimiento en Toledo, por muerte de un criado suyo, pero no hemos podido comprobar si la merced se llevó a efecto ${ }^{57}$. En el caso de Cuenca Yolanda Guerrero y José María Sánchez Benito constatan que sólo una parte mínima de los oficiales con derecho a voto fueron durante el siglo XV miembros de la alta nobleza terrateniente afincados en la ciudad, respecto a los cuales sostienen que en sentido estricto no pueden ser considerados miembros de la oligarquía, pues "ésta siempre se define por su condición de ser únicamente una élite de poder urbana" ${ }^{58}$. Sin entrar a discutir la validez de esta aseveración, lo cierto es que fuesen o no minoritarios, también en esta ciudad hubo regidores procedentes de familias de alta nobleza que desempeñaron un papel muy destacado en la vida política local. Así, desde este punto de vista, cabe resaltar figuras como la de Luis Hurtado de Mendoza, hijo del señor de Cañete, Juan Hurtado de Mendoza, y tío del guardamayor Diego Hurtado de Mendoza, a nuestro entender la figura más influyente de la escena política conquense a principios del siglo XVI, con el cual mantuvo, sin embargo, una áspera rivalidad, que tenía su origen en disputas sucesorias $^{59}$, y la de Rodrigo Manrique, hermano menor del referido guardamayor, que sucedió en el regimiento al mencionado Luis Hurtado de Mendoza, su tío, a raíz de su muerte en el año $1508^{60}$. Otro individuo procedente de las filas de la alta nobleza, Luis Carrillo de Albornoz, alcalde mayor de los hijosdalgo y señor de Torralba y Beteta, regidor de Cuenca desde 1506, llegó a erigirse en la máxima autoridad de la ciudad durante los meses de la revuelta comunera ${ }^{61}$. Y, por fin, también interesa recordar en este contexto que el mayordomo Andrés Cabrera, marqués de Moya, fue por breve espacio de tiempo regidor de Cuenca hasta que renunció el oficio en 1479 en su criado Rodrigo de la Fuente ${ }^{62}$, mientras que su hermano Alonso de Cabrera

${ }^{56} \mathrm{AGS}, \mathrm{RGS}$, VII-1522. Cabe recordar que Gutierre de Cárdenas, fundador del mayorazgo de los marqueses de Elche, fue nombrado veinticuatro de Sevilla en 1480. Vid. Juan de Mata CARRIAZO (Dir.), El tumbo de los Reyes Católicos del concejo de Sevilla, vol. III, Sevilla, 1968, pp. 136-7, Medina del Campo, 20-XII-1480. Sobre este linaje Vid. Juan Ramón PALENCIA HERREJÓN, Estrategia patrimonial y jerarquía del linaje: Los mayorazos de la casa ducal de Maqueda en el siglo XVI, "Historia. Instituciones. Documentos", 29 (2002), pp. 337-355.

${ }^{57}$ Vid. AGS, Cámara-Personas, leg. 22. Memorial de las cosas que se consultaron con el rey en 19-XI-1517. Se anota en concreto lo siguiente: "El marqués de Villena suplica se le mande despachar las provisiones del regimiento de Toledo de que V.A. le hizo merced por fallecimiento de su criado".

${ }^{58}$ Yolanda Guerrero NAVARrete y José María SÁnChEZ Benito, Cuenca en la Baja Edad Media: Un sistema de poder, Cuenca, 1994, p. 139.

${ }^{59}$ Vid. Máximo DiAgo HeRnANDO, La alta nobleza en la vida, cit. pp. 129-30.

${ }^{60}$ AGS, RGS, VIII-1508. Nombramiento de Rodrigo Manrique como regidor de Cuenca por vacación de Luis Hurtado de Mendoza, su tío, fallecido. Sobre el destacado papel desempeñado por Rodrigo Manrique en Cuenca durante la revuelta comunera Vid. Máximo DIAGO HERNANDO, El conflicto de las Comunidades en Cuenca, cit.

${ }^{61}$ Vid. Máximo Diago Hernando, El conflicto de las Comunidades en Cuenca, cit.

${ }^{62} \mathrm{AGS}, \mathrm{RGS}$, IX-1479, fol. 10. Interesa hacer constar que Andrés Cabrera, marqués de Moya, también había sido nombrado por los Reyes Católicos en 1477 veinticuatro y alcalde de las alcabalas de Sevilla y, más adelante, en 1482 estos monarcas nombraron veinticuatro de esta misma ciudad a su hermano, el comendador Pedro de Cabrera. Vid. Juan de Mata CARRIAZO 
desempeñó este mismo oficio durante gran parte del reinado de los Reyes Católicos, para luego renunciarlo en su primogénito Jerónimo de Cabrera ${ }^{63}$.

También en las principales ciudades andaluzas nos encontramos con numerosos ejemplos de miembros de la alta nobleza que desempeñaron oficios de regidores, en ellas denominados "veinticuatros" . En Sevilla en concreto cabe destacar en primer lugar que los almirantes mayores de Castilla, del linaje de los Enríquez, por razón del desempeño de dicho oficio ejercían una veinticuatría en esta ciudad, con voz y voto, que fue formalmente anexionada al almirantazgo por virtud de un privilegio de Fernando el Católico del año $1478^{64}$. Por su parte nos consta que el conde de Feria, Gómez Suárez de Figueroa, fue nombrado veinticuatro en enero de 1491, en sustitución de Juan de Guzmán ${ }^{65}$, aunque permaneció poco más de un año en el desempeño del oficio, pues en 1492 lo renunció a favor de Juan de Saavedra, hijo de Fernán Arias de Saavedra ${ }^{66}$. Alfonso Carrillo de Acuña, guarda mayor del rey, en 1491 recibió por merced una veinticuatria que llevaba consigo aneja la tenencia de la fortaleza concejil de Santa Olalla ${ }^{67}$, la cual renunció en 1494 a favor de su hijo Pedro Suárez de Castilla ${ }^{68}$. El poderoso linaje de los Ponce de León, duques de Arcos, también proporcionó regidores al concejo hispalense, como Luis Ponce de León, que lo fue hasta 1475, cuando renunció el oficio en García Enríquez ${ }^{69}$, o Manuel Ponce de León, hijo del conde de

(Dir.), El tumbo de los Reyes Católicos del concejo de Sevilla, vol. II, Sevilla, 1968, p. 62, Sevilla, 2-VIII-1477. Nombramiento del mayordomo Andrés Cabrera como veinticuatro y alcalde de las alcabalas de Sevilla, por muerte de Fernán García de Córdoba. Y Vol. III, Sevilla, 1968 pp. 223-4, Córdoba, 25-VI-1482. Nombramiento del comendador Pedro de Cabrera, hermano del marqués de Moya, como veinticuatro de Sevilla, por renuncia de Gonzalo de Estúñiga, su suegro.

${ }^{63}$ Vid. María del Pilar RÁBADE OBRADÓ, Los judeoconversos en la Corte y en la época de los reyes Católicos, Universidad Complutense, Madrid, 1990, p. 566.

${ }^{64}$ En 1477 la reina Isabel la Católica hizo merced al almirante Alfonso Enríquez del oficio de veinticuatro de Sevilla que había quedado vacante por muerte de Alfonso de Velasco. Vid. Juan de Mata CARRIAZO (Dir.), El Tumbo de los Reyes Católicos del concejo de Sevilla, vol. II, Sevilla, 1968, pp. 83-4, Sevilla, 8-IX-1477. En la misma fecha también le hizo merced del oficio de juez mayor de las suplicaciones de Sevilla y su Tierra, también vacante por muerte de Alfonso de Velasco. Ibíd., pp. 84-5. Más adelante el almirante solicitó al rey Fernando el Católico que anexionase el dicho oficio de veinticuatría al oficio del almirantazgo, y así lo concedió éste por privilegio de Sevilla, 15-VII-1478. Ibíd., pp. 227-9.

${ }^{65}$ Juan de Mata CARRIAzo (Dir.), El Tumbo de los Reyes Católicos del concejo de Sevilla, vol. V, Sevilla, 1971, pp. 198-9. Provisión de Reyes Católicos de Sevilla, 30-I-1491.

${ }^{66} I b i ́ d .$, pp. 323-4. Provisión de Reyes Católicos de Santa Fe, 27-III-1492.

${ }^{67}$ Ibíd., pp. 239-40. Provisión de Reyes Católicos de Vega de Granada, 19-VIII-1491. A este mismo Alonso Carrillo los reyes unos anos antes le habían hecho merced de las tenencias de otras fortalezas concejiles de Sevilla, como las de Lebrija y Alcalá de Guadaira. Ibíd., vol. IV, pp. 8-9 (provisiones de 4-III-1485 sobre la fortaleza de Lebrija), y pp. 267-8 (provisiones de 21-II-1488 sobre la fortaleza de Alcalá de Guadaira). La tenencia de Álcalá de Guadaira la obtuvo, no obstante, por permuta acordada con Don Diego López de Haro, a quien cedió la de Lebrija (Ibíd., p. 271).

${ }^{68}$ Marcos FERnÁnDEZ, Pilar OSTOS y Ma a Luisa PARDO, El Tumbo de los Reyes Católicos del concejo de Sevilla. VII. 1494-1497, Fundación Ramón Areces, Madrid, 1998, pp. 161-3, Madrid, 22-XII-1494.

${ }^{69}$ Vid. Juan de Mata CARRIAZO (Dir.) El Tumbo de los Reyes Católicos del concejo de Sevilla. I, Sevilla, 1929-1968, pp. 58-9, Valladolid, 22-V-1475. 
Arcos, que fue nombrado en 1477 por renuncia de Juan Cataño ${ }^{70}$. Por su parte los Velasco, Condestables de Castilla, que poseían gran parte de su patrimonio señorial en la submeseta norte, estuvieron representados en el cabildo sevillano por Iñigo Fernández de Velasco, que llegó a ser Condestable por sucesión de su hermano Bernardino en 1512, el cual recibió merced de un oficio de veinticuatro de la capital hispalense en $1478^{71}$. Y a una rama secundaria de este mismo linaje, con implantación señorial en Andalucía, pertenecía Alonso de Velasco, señor de Gandul y Marchenilla, que fue veinticuatro de Sevilla, además de juez mayor de las suplicaciones de la ciudad y su Tierra, hasta su muerte en el año $1477^{72}$. Por fin, sin que la relación resulte ni mucho menos exhaustiva, Luis Méndez Portocarrero, señor de Palma, fue veinticuatro de Sevilla desde $1494^{73}$ hasta su muerte en el reino de Nápoles, donde servía como capitán, en el año 1503, fecha en que le sucedió en el oficio su hijo primogénito Luis ${ }^{74}$. Pero, además, desempeñó otros destacados oficios de gobierno en otras ciudades andaluzas, como Córdoba, donde fue "voto y voz mayor", y Écija, donde sirvió como alcalde y alguacil mayor, regidor y tenente de los alcázares. Y en todos estos oficios logró también sucederle en 1503 su primogénito Luis, primer conde de Palma ${ }^{75}$.

$\mathrm{Al}$ igual que en Sevilla, también en Córdoba, a juzgar por los datos que proporciona Margarita Cabrera, fueron relativamente numerosos los miembros de familias de la alta nobleza, preferentemente segundones, que desempeñaron el oficio de veinticuatros. En concreto refiere esta autora los ejemplos de los señores de El Carpio - Garcí Méndez de Sotomayor y su hijo Luis Méndez- los señores de Fernán Núñez-Alfonso y Fernando de los Ríosel señor de Alcaudete y Montemayor, Martín Alfonso de Sotomayor; Martín de Córdoba, hijo del primer conde de Cabra, y el célebre Gonzalo Fernández de Córdoba, conocido como el Gran Capitán, que era hijo del señor de

${ }^{70}$ Juan de Mata CARRIAZO (Dir.), El Tumbo de los Reyes Católicos del concejo de Sevilla. II, Sevilla, 1968, pp. 113-4, Jerez de la Frontera, 14-X-1477. Manuel Ponce de León renunció dicho oficio en 1479 en Diego de Guzmán, hijo de Juan de Guzmán, señor de La Algaba. Ibíd,. pp. 383-4, Trujillo 18-VIII-1479.

${ }^{71}$ Juan de Mata CARRIAZO (Dir.), El Tumbo de los Reyes Católicos del concejo de Sevilla. II, Sevilla, 1968, pp. 397-8, Córdoba, 10-XII-1478. Se hace merced a Iñigo de Velasco del oficio de veinticuatro que había quedado vacante por la rebeldía de Martín de Sepúlveda, militante en el bando del rey de Portugal.

${ }^{72} \mathrm{Cfr}$. nota 64.

${ }^{73}$ Ibíd., pp. 80-2, Segovia, 20-VIII-1494.

${ }^{74}$ Marcos FERNÁNDEZ y Pilar OSTOS, El Tumbo de los Reyes Católicos del concejo de Sevilla. XII, 1503-1509, Fundación Ramón Areces, Madrid, 2004, pp. 72-4, Segovia, 15-VIII-1503.

${ }^{75}$ Vid. AGS, RGS, VII-1503 (1 ${ }^{\circ}$ ), fol. 62. Merced del oficio de "voto y voz mayor" de Córdoba a Luis Portocarrero, señnor de Palma, por vacación de su padre. Ibíd. Fọl. 63. Merceed al mismo de la alçaldía y alguacilazgo mayor de Ecija. Ibíd. Fol. 96 . Merced al mismo del oficio de regidor de Ecija, por vacación de su padre. Además también se hizo merced de las tenencias de las fortalezas de Alora y Constantina, y de los alcázares de la ciudad de Ecija (Ibíd., fols. 64, 65 y 66). 
Aguilar $^{76}$, el cual poco después de ser nombrado regidor de Córdoba pasó a serlo también de la ciudad de Granada ${ }^{77}$.

Pero este fenómeno no fue sólo exclusivo de las grandes ciudades, capitales de reino, con representación en Cortes. También lo podemos constatar, aunque a menor escala, en las de segundo rango. Así, a título ilustrativo cabe añadir al ya mencionado ejemplo de Écija, ciudad donde fue regidor Luis Méndez Portocarrero, señor de Palma, y luego lo fueron su hijo y su nieto ${ }^{78}$, el de Úbeda, donde un hijo del conde de Paredes, del linaje de los Manrique, accedió al regimiento en $1523^{79}$, y el de Marbella, donde en 1488 recibió merced de un oficio de regidor el conde de Ribadeo, Pedro de Villandrando, que ya entonces era regidor de Valladolid, y al mismo tenente de la fortaleza realenga de la referida ciudad andaluza desde su conquista a los nazaríes $^{80}$.

En suma, la presencia de miembros de la alta nobleza entre los regidores fue un fenómeno habitual en muchas de las principales ciudades castellanas de la meseta y de Andalucía, aunque alcanzó un desarrollo muy desigual de unas a otras. Sin ninguna duda en prácticamente todas las ciudades representaron una minoría en términos porcentuales, pero que habitualmente gozó de una enorme influencia. Y, en cualquier caso, se ha de resaltar que no eran sólo estos individuos los que conferían a los regimientos de las grandes ciudades castellanas su fuerte perfil nobiliario, sino también los otros muchos regidores reclutados entre los linajes de nobleza media, muchos de ellos titulares de pequeños señoríos de vasallos, que hubo en estas mismas ciudades. La gran cantidad de pequeños señoríos constituidos en Castilla en los siglos XIV y XV a favor de linajes de nobleza media que conformaron el núcleo duro de las oligarquías de la mayoría de las grandes ciudades castellanas, incluida Burgos, parece haber pasado desapercibida para muchos autores que han abordado la caracterización de estas oligarquías desde una perspectiva global. Es el caso, por ejemplo, de Fernández i Trabal quien por un lado reconoce que en las oligarquías de las villas y ciudades castellanas, aragonesas y valencianas de frontera, se dio un predominio absoluto de la pequeña nobleza urbana de caballeros villanos e hidalgos, si bien por otro lado sostiene que se trató de élites exclusivamente urbanas, que excluyeron del ejercicio del poder a la "nobleza rural titular de jurisdicciones y señoríos". Y pone como ejemplo para probar su tesis el caso de la ciudad valenciana de

\footnotetext{
${ }^{76}$ Margarita CABRERA SÁNCHEZ, op. cit., pp. 110 y ss.

${ }^{77}$ Su nombramiento para Córdoba en AGS, RGS, XI-1497, fol. 11. Y el de Granada en RGS, VIII-1499, fol. 22 .

${ }^{78}$ Sobre la permanencia del oficio en la tercera generación, aunque en principio sólo en depósito, Vid. AGS, RGS, III-1522. Provisión disponiendo que Luis de Portocarrero, conde de Palma, tenga en depósito el regimiento que habia quedado vacante por muerte de Luis de Portocarrero, "entre tanto que no se provea otra cosa".

${ }^{79}$ AGS, RGS, I-1523. Regimiento de Úbeda para Pedro Manrique, hijo del conde de Paredes, por renuncia de Sebastián de Baeza.

${ }^{80} \mathrm{El}$ conde de Ribadeo renunció a su oficio de regidor de Marbella en 1494 a favor de Nuño de Villasán. Vid. AGS, RGS, VII-1494, fol. 66. El conde de Ribadeo había sido nombrado tenente de la fortaleza de Marbella por los Reyes Católicos.
} 
Orihuela, donde la familia más importante del término fue sistemáticamente excluida del concejo urbano por su condición de noble ${ }^{81}$. Nada que objetar por lo que respecta a las ciudades aragonesas y valencianas, pero sí mucho por lo que toca a las ciudades castellanas, donde el número de oficiales, y en concreto regidores, que fueron señores de vasallos fue enorme ya en el siglo $\mathrm{XV}$, y se multiplicó durante los siglos XVI y XVII como consecuencia de las operaciones de venta de señoríos puestas en marcha por la monarquía a partir del reinado de Felipe II.

\section{Miembros de la alta nobleza como procuradores a Cortes}

La facilidad con que los miembros de linajes de la alta nobleza se integraron en las instituciones de gobierno local de las principales ciudades castellanas queda también puesta de manifiesto en el número relativamente elevado de individuos pertenecientes a este grupo que actuaron como procuradores a Cortes por dichas ciudades a lo largo del siglo XV y durante las dos primeras décadas del siglo XVI. Así, para el período anterior al reinado de los Reyes Católicos, cabe citar, entre otros ejemplos ilustrativos de este singular fenómeno, la presencia de Juan de Luna, señor de Magaña, Cornago y Jubera, como procurador por Soria en las Cortes de $1453-54^{82}$, del alférez Juan de Silva como procurador por Toledo en las de 1445, de Lope Vázquez de Acuña como procurador por Cuenca en las de 1447, del Condestable Miguel Lucas de Iranzo como procurador de Jaén en el ayuntamiento de Madrid de 1457-58, del conde de Ribadavia como procurador por Toledo en las Cortes de Santa María de Nieva de 1473, o la de dos hijos del marqués de Santillana, Pedro y Juan de Mendoza, como procuradores por Guadalajara en estas mismas Cortes ${ }^{83}$.

Durante los reinados de los Reyes Católicos y de su nieto Carlos I, en contra de lo que habría cabido esperar, dados los esfuerzos que los primeros realizaron para acabar con las prácticas intervencionistas de los miembros de la alta nobleza en la vida política de las ciudades realengas, la presencia de representantes de este grupo sociopolítico como procuradores designados por las ciudades con representación en Cortes resulta un fenómeno incluso más frecuente que en los reinados de Juan II y Enrique IV. Así, limitándonos a dejar sólo constancia de los casos de los nobles titulados, tenemos que el conde de Luna fue procurador por León a las Cortes de 1520 y de 1527, el conde de Tendilla lo fue por Granada a las de 1515, mientras que su hijo, el regidor Luis de Mendoza, lo había sido por la misma ciudad a las de 1506; el conde de Cabra lo fue por Córdoba nada menos que en tres

\footnotetext{
${ }^{81}$ Josep FERNÁNDEZ I TRABAL, La oligarquía urbana catalana, cit. p. 302.

${ }^{82}$ Sobre este personaje, pariente y valedor del Condestable Don Álvaro de Luna, Vid. Máximo DIAGO HERNANDO, El alcaide Juan de Luna: un hombre al servicio del Condestable Don Alvaro en la región soriana, "Celtiberia", 81-82 (1991), pp. 59-85.

${ }^{83}$ Tomamos los datos de César OLIVERA SERRANO, Las Cortes de Castilla y León y la crisis del reino (1445-1474). El registro de Cortes, Burgos, 1986.
} 
ocasiones, en 1499, 1505 y 1515, mientras que el marqués de Priego lo fue por la misma ciudad en 1500; el duque de Medinasidonia, fue procurador a Cortes por Sevilla en 1515, mientras que Luis Méndez Portocarrero, señor de Palma, lo fue en 1498; el conde de Ribadeo, Pedro de Villandrando, fue procurador a Cortes por Valladolid en 1498, y por fin, por citar dos casos más tardíos, los marqueses de Poza y Cañete fueron procuradores por Burgos y Cuenca, respectivamente, a las Cortes de $1532^{84}$.

En suma, por tanto, las informaciones aportadas no dejan lugar a dudas sobre la fuerte presencia en las instituciones de gobierno local de las principales ciudades castellanas de miembros de la alta nobleza, en especial durante el siglo XV y en las primeras décadas del siglo XVI. Pero, además, se ha de tener en cuenta que los miembros de este grupo sociopolítico recurrieron también en esta época a otros procedimientos para influir de forma determinante en la vida política de dichas ciudades, entre los que cabe destacar, por su difusión y eficacia, el del pago de "acostamientos" a otros oficiales de gobierno urbano, miembros de la pequeña nobleza, mediante los que conseguían incorporarlos a sus clientelas, asegurándose su apoyo en las empresas de carácter político o militar que acometiesen. No vamos a entrar aquí, sin embargo, a profundizar en el análisis de esta práctica, que tuvo importantes repercusiones sobre el devenir de la vida política de las ciudades castellanas a fines de la Edad Media, caracterizada por la omnipresencia de las luchas de bandos.

\section{Participación de la nobleza en las instituciones de gobierno de las ciudades de la Corona de Aragón}

En claro contraste con las ciudades de la Corona de Castilla, la mayor parte de las de la Corona de Aragón excluyeron durante los siglos bajomedievales de forma explícita a los miembros del estamento noble, tantos grandes señores de vasallos como simples infanzones, de sus órganos de gobierno. Este contraste ha tendido a ser minusvalorado por algunos autores, que han insistido por el contrario en destacar la existencia de unos rasgos comunes a los grupos dominantes de todas las ciudades peninsulares, aplicándoles la común denominación de patriciados ${ }^{85}$. Creemos, no obstante, que las diferencias existentes entre las oligarquías urbanas de unos y otros reinos

\footnotetext{
${ }^{84}$ Tomamos los datos de Juan Manuel CARRETERo ZAMORA, Cortes, monarquía, ciudades. Las Cortes de Castilla a comienzos de la época moderna (1476-1515), Siglo XXI, Madrid, 1988 . pp. 425-38. Para el reinado de Carlos I. Vid. José Ignacio FORTEA PEREZ, Las Cortes de Castilla en los primeros años del reinado de Carlos V, 1518-1536, en Ernest BELENGUER CEBRIÄ De la unión de coronas al Imperio de Carlos V, Madrid, 2001, pp. 411-444. En particular p. 412.

${ }^{85}$ Es el caso, por ejemplo, de José María Monsalvo AnTón, La Baja Edad Media, cit. p. 171. Refiriéndose a las ciudades de la Corona de Castilla y de la Corona de Aragón, y más en concreto de Cataluña, afirma que "desde el punto de vista de la composición social de los gobiernos urbanos en todas partes predominó-salvo paréntesis momentáneos y con correcciones y contrapesos-el elemento patricio, es decir, la hegemonía de los grupos o estamentos más ricos y poderosos".
} 
fueron muy importantes, y justifican el que se les apliquen diferentes calificativos.

Dentro de la Corona de Aragón también cabe observar, por otra parte, importantes contrastes, de los que trataremos de dar cuenta a continuación, mediante un breve y somero repaso a la situación vigente en cada uno de los reinos en lo que a criterios de admisión de miembros de la nobleza en los órganos de gobierno urbano se refiere.

\section{Principado de Cataluña}

Entre los reinos de la Corona de Aragón destaca el principado de Cataluña por ser el ámbito donde la exclusión de la nobleza de los órganos de gobierno urbano se impuso de forma más radical durante el período bajomedieval. En las ciudades catalanas, en efecto, los miembros del estamento nobiliario no pudieron integrarse en las sociedades políticas urbanas durante los siglos XIV y XV. Por el contrario, en ellas, según resume Fernández i Trabal, la minoría dominante estuvo integrada por familias de ciudadanos preeminentes, mercaderes, juristas y propietarios terratenientes, que alcanzaron la fuerza suficiente para no permitir la intromisión de la aristocracia militar en el gobierno urbano y mantener de este modo su hegemonía social y política ${ }^{86}$.

La ciudad más importante del principado era la de Barcelona, en donde llegó a consolidarse durante el período medieval un grupo patricio, muy influyente tanto desde el punto de vista político como social, constituido por los llamados "ciutadans honrats", que eran en su mayor parte mercaderes y financieros enriquecidos, reconvertidos en rentistas. En todo el período medieval este grupo nunca llegó a ser formalmente reconocido como noble, y hubo que esperar al año 1510 para que todos sus miembros fuesen ennoblecidos de forma colectiva por virtud de un privilegio expedido por el rey Fernando el Católico, que tuvo su contrapartida en la admisión de los miembros de la pequeña nobleza, es decir, los caballeros y generosos, al desempeño de oficios en los órganos de gobierno barceloneses, al pasar a reservárseles una plaza en el colegio de "consellers" y dieciséis en el "Consell de Cent". Así, a comienzos de la Edad Moderna, miembros del estamento noble tuvieron por fin acceso a las instituciones de gobierno de la capital del principado, aunque sólo los que pertenecían a la pequeña nobleza, puesto que los miembros de linajes de alta nobleza tuvieron que esperar hasta 1621 para que se les admitiese en dichas instituciones ${ }^{87}$. Y, siguiendo el ejemplo de Barcelona, también poco después en otras ciudades catalanas se admitió a

\footnotetext{
${ }^{86}$ Josep FERNÁNDEZ TRABAL, La oligarquía urbana catalana, cit., pp. 299-328.

${ }^{87}$ Vid. James S. AMELANG, Honored Citizens of Barcelona. Patrician Culture and Class Relations, 1490-1714, Princeton University Press, 1986 . Y Marie Claude GERBET, Patriciat et Noblesse à Barcelone à l'époque de Ferdinand le Catholique. Modalités et limites d'une fusion, en Villes et societés urbaines au Moyen Age. Hommage à M. le Professeur Jacques Heers, París, 1994, pp. 133-40.
} 
miembros de la baja nobleza al desempeño de las magistraturas urbanas, sin que se viesen forzados a renunciar previamente al privilegio militar ${ }^{88}$.

\section{Reino de Aragón}

En el reino de Aragón la situación estuvo mucho más diversificada que en Cataluña durante el período bajomedieval. En su capital, Zaragoza, los miembros del estamento noble, incluidos los que estaban avecindados en la ciudad y eran parroquianos de alguna de sus parroquias, quedaron radicalmente excluidos de cualquier participación en las instituciones de gobierno urbano. Por este motivo no podían asistir a las asambleas de parroquia cuando éstas se reunían para dilucidar asuntos de carácter político, mientras que sí se les permitía el acceso a ellas cuando se fuesen a tratar asuntos de carácter religioso, piadoso o de beneficencia ${ }^{89}$.

Esta política de sistemática exclusión de la nobleza de los órganos de gobierno local de Zaragoza causó malestar entre los infanzones aragoneses, y así lo ponen de manifiesto las sucesivas protestas presentadas en Cortes por los representantes de este brazo a partir de 1367, que, no obstante, no fueron atendidas, ante la firme oposición que manifestaron los ciudadanos zaragozanos $^{90}$. Y de ahí que no resultasen infrecuentes los casos de caballeros e infanzones que voluntariamente renunciaron a su condición noble para desempeñar oficios de la capital aragonesa, que de otro modo les quedaban vedados ${ }^{11}$.

Una actitud más tolerante hacia los miembros del estamento noble se observó en otras ciudades del reino como Huesca, Jaca y Barbastro, en las que se llegó a admitir su coparticipación, junto con los ciudadanos, en el gobierno municipal, aunque sin ocupar una posición dominante, como la que les correspondió en las ciudades castellanas. Así, en Huesca los ciudadanos firmaron un pacto con los infanzones en 1322, que contemplaba un reparto de los oficios, en el que los ciudadanos se reservaron los puestos de mayor peso político, y a cambio los infanzones quedaron implicados en los repartos vecinales de las contribuciones, con excepción de los impuestos reales y el monedaje, pero no de las cenas. También se reconoció entonces a dichos infanzones el derecho a asistir a las reuniones concejiles en pie de igualdad con los ciudadanos, salvo a aquéllas en las cuales se votasen las ayudas al

\footnotetext{
${ }^{88}$ Josep FERNÁNDEZ Y TRABAL, La oligarquía urbana catalana, cit., p. 324.

${ }^{89}$ Vid. Enrique MAINÉ BURGUETE, Infanzones contra ciudadanos. Luchas por el poder en la parroquia de la Magdalena (Zaragoza), "Aragón en la Edad Media, XIV-XV. Homenaje a la profesora Carmen Orcástegui Gros", vol. II, Zaragoza, 1999, pp. 941-53. Susana LoZANO GRACIA, La parroquia como espacio de control político y social: Las reuniones parroquiales de Santa María la Mayor (1450-1475), "Actas II Simposio de Jóvenes Medievalistas. Lorca 2004", Murcia, 2006, pp. 111-129. EADEM, Las parroquias y el poder urbano en Zaragoza durante los siglos XIV y XV, “En la España Medieval”, 29 (2006), pp. 135-51.

${ }^{90}$ Vid. Enrique MaInÉ BURGUeTe, art. cit., p. 942.

${ }^{91} I b i ́ d$. pp. 941-2. También proporciona algunos ejemplos de miembros de la pequeña nobleza que ingresaron en el estamento de ciudadanos honrados de Zaragoza, Susana LOZANO GRACIA, Las parroquias y el poder urbano, cit., p. 149.
} 
monarca. Pero con el transcurso del tiempo los nobles fueron poco a poco perdiendo protagonismo en la escena política oscense, hasta terminar por desaparecer de la misma, de forma que a partir de 1481 ya no hay constancia de la participación de infanzones en los órganos de gobierno local ${ }^{92}$.

En las ciudades de la llamada Extremadura aragonesa el grupo dirigente estuvo constituido por individuos propietarios de armas y caballos, que no formaban parte de la nobleza de linaje, pero que disfrutaban de ciertos privilegios que les diferenciaban del grueso de la población pechera, los cuales accedían al desempeño de los oficios de gobierno local mediante una mecánica electoral que tenía como pieza clave la parroquia ${ }^{93}$. En muchos aspectos estos grupos dirigentes de las ciudades aragonesas llamadas "de frontera" se asemejaban a los de caballeros villanos que gobernaron en muchas de las ciudades castellanas en los siglos XII y XIII. Pero, mientras que en Castilla en el transcurso de los siglos bajomedievales las oligarquías de caballeros villanos terminaron quedando formalmente reconocidas como nobles, pasando a distinguirse a partir de entonces en ellas entre un grupo dominante de hidalgos, y un grupo intermedio de caballeros de cuantía, que eran pecheros con capacidad económica para mantener caballo y armas ${ }^{94}$, en las aragonesas no hay constancia de que se produjese tal transformación. Por el contrario, nos consta que en estas ciudades en los siglos XIV y XV aquellos vecinos que tenían reconocida la condición noble, es decir, los infanzones, estaban excluidos del ejercicio de oficios de gobierno local, porque no se les consideraba miembros de pleno derecho de la comunidad política urbana, mientras que éste no era el caso de los caballeros no nobles, que sí podían desempeñar dichos oficios. Así, la exclusión de los infanzones del gobierno local está constatada en Teruel ${ }^{95}$, y también en Calatayud, aunque en este caso la documentación aporta algunas informaciones contradictorias que plantean ciertos interrogantes ${ }^{96}$. Y, por lo que respecta a Daroca, las ordenanzas aprobadas en 1359 impusieron la obligación de pechar como requisito para desempeñar oficios del concejo, por lo que en consecuencia quedaron

\footnotetext{
${ }^{92}$ Vid. Carlos LALIENA CORBERA y Ma Teresa IRANZO MuÑío, Poder, honor y linaje en las estrategias de la nobleza urbana aragonesa (Siglos XIV-XV), "Revista d' Historia Medieval", 9
(1998), pp. 55-58. Y María Teresa IRANZO MUNí, El grupo aristocrático en Huesca en la Baja Edad Media: bases sociales y poder político "Les sociêtés urbaines en France méridionale et en Péninsule Ibérique au Moyen Âge", Paris, 1991, pp. 183-202. p. 58 .

${ }^{93} \mathrm{Vid}$. Carlos Laliena CoRbera y M ${ }^{\mathrm{a}}$ Teresa Iranzo MuÑío, Poder, honor y linaje, cit.

${ }^{94}$ Vid. Máximo DiAGO HERNANDO, Caballeros e hidalgos en la Extremadura castellana medieval (siglos XII-XV), "En la España Medieval", 15 (1992), pp. 31-62.

${ }^{95} \mathrm{Vid} . \mathrm{M}^{\mathrm{a}}$. Isabel FALCón PÉREZ, Sociedad cristiana en el mundo urbano aragonés, en La Península Ibérica en la era de los descubrimientos. 1391-1492, Sevilla, 1997, pp. 967-998.

${ }^{96}$ Vid. Máximo DiAgo Hernando, Calatayud en la Baja Edad Media. Organización sociopolítica y actividades económicas, "Áctas del VI Encuentro de Estudios Bilbilitanos", Centro de Estudios Bilbilitanos-Institución Fernando el Católico, Calatayud, 2005, pp. 237-274, en especial pp. 244-5.
} 
excluidos de este órgano de gobierno los infanzones que no estuviesen dispuestos a renunciar a sus privilegios ${ }^{97}$.

\section{Reino de Valencia}

De todos los reinos de la Corona de Aragón, aquél en que se reconoció un papel político más activo a los miembros del estamento noble en las instituciones de gobierno urbano fue el de Valencia. En concreto desde esta perspectiva cabe destacar el caso de la capital del reino, donde seis miembros del estamento noble entraban a formar parte del Consell de Cent, junto con 4 juristas, 2 notarios, 48 representantes de las 12 parroquias, a razón de 4 por parroquia, y 2 representantes por cada gremio laboral, por lo cual representaban una exigua minoría en esta gran asamblea. Mayor peso tenian los miembros de este estamento en el colegio de jurados, donde se les asignaron dos de los seis oficios de que se componía ${ }^{98}$. En cualquier caso el desempeño de estos oficios, que eran de renovación anual, como la mayoría en Valencia, no aseguró a los miembros de la pequeña nobleza, caballeros y generosos, residentes en la ciudad del Turia una fuerte influencia en la vida política local, en la que alcanzaron mayor protagonismo otros grupos sociales. $\mathrm{Y}$, por tanto, desde este punto de vista también esta ciudad ofrece un fuerte contraste con las ciudades castellanas. Para percibirlo basta con plantear una somera comparación con la ciudad de Sevilla, que por su potencial económico y demográfico, puede parangonarse con Valencia en los siglos XIV y XV. Mientras que la capital andaluza era gobernada por un consistorio compuesto de oficiales en su mayor parte vitalicios, que recibían sus nombramientos del rey, y entre los cuales abundaban miembros de la alta nobleza, con extensos señoríos en Andalucía, y en ocasiones también en otras regiones de Castilla, a los que se sumaban numerosos miembros de linajes de nobleza media, terratenientes y a veces incluso señores de vasallos, en la ciudad del Turia el número de vecinos que tomaban parte activa en las instituciones de gobierno era elevadísimo, tenían una muy diversificada procedencia social, y además se renovaba con rapidez, puesto que los cargos se desempeñaban durante períodos muy breves de tiempo. Ciertamente entre estos vecinos había algunos nobles, pero en ningún caso representantes de linajes de la más alta nobleza, como los que encontramos en Sevilla. Y la capacidad de influir sobre el devenir de la vida política local de que disfrutaban estos representantes de la pequeña nobleza valenciana era notablemente menor que la que alcanzaron en Sevilla miembros de la alta nobleza andaluza como los duques de Medinasidonia o los duques de Arcos, quienes tenían tras de sí importantes sectores de la sociedad política local, a los que podían movilizar con relativa facilidad cuando lo precisaban.

\footnotetext{
58. ${ }^{97}$ Vid. Carlos Laliena Corbera y M ${ }^{\mathrm{a}}$. Teresa Iranzo MuÑío, Poder, honor y linaje, p.

${ }^{98}$ Ernest BelEnguer CEBrià, València en la crisi del segle XV, Barcelona, 1976, pp. 24 y siguientes.
} 


\author{
II. LA NOBLEZA \\ EN EL GOBIERNO DE LAS CIUDADES \\ DEL IMPERIO ALEMÁN
}

Uno de los grandes clásicos de la historiografía alemana, la profesora Edith Ennen, propuso una visión global sobre la ciudad europea medieval basada en la contraposición entre el mundo germánico, en el que los nobles habrían manifestado una declarada aversión hacia las ciudades, por un lado, y el mundo mediterráneo, heredero de la tradición romana, y caracterizado, por tanto, por una fuerte inclinación hacia la vida urbana de la nobleza, por otro $^{99}$. Para justificar su punto de vista, esta autora propuso de forma preferente ejemplos tomados de las ciudades italianas, aunque no dejó de incluir, a título complementario, otros procedentes del sur de Francia y de la Península Ibérica, si bien hay que reconocer que estos ultimos son escasos y poco convincentes, a la vez que no recogen la notable variedad de situaciones que desde la perspectiva de las relaciones establecidas entre nobleza y ciudades se dieron en los reinos hispanos. Por otra parte esta visión, al margen de lo que pueda tener de simplificadora, se basa en la asunción de un modelo historiográfico que gozó de gran prestigio en el mundo académico germano en el siglo XIX y gran parte del siglo XX, que atribuye la implantación de las instituciones de autogobierno en las ciudades europeas al norte de los Alpes, que propició la consolidación de un estamento "ciudadano" o "burgués" diferenciado de la nobleza y del campesinado, a la acción de mercaderes de condición libre ${ }^{100}$.

Este modelo historiográfico, que prácticamente no reconoce ningún papel a la nobleza en las estructuras sociopolíticas de las ciudades alemanas, fue sometido, sin embargo, durante la segunda mitad del siglo XX a una sistemática revisión por una corriente historiográfica que se ha esforzado por poner de manifiesto el destacado papel desempeñado por los ministeriales en las primeras fases de afianzamiento de la autonomía política de las ciudades frente a sus señores laicos y eclesiásticos, que propició la incorporación de muchos de ellos a sus grupos gobernantes ${ }^{101}$.

Los ministeriales eran individuos de origen servil, integrados en la "familia" de su correspondiente señor, que les podía imponer restricciones en la libertad de disposición de sus bienes y personas, incluso a la hora de contraer matrimonio. Pero en la práctica, a pesar de esta condición servil,

\footnotetext{
${ }^{99}$ Vid. Edith ENNEN, Frühgeschichte der europäischen Stadt, Bonn, 1981 ( $1^{\mathrm{a}}$. Ed. en 1953). EADEM, Die europäische Stadt des Mittelalters als Forschungsaufgabe unserer Zeit, en "Gesammelte Abhandlungen zum europäischen Städtewesen und zur rheinischen Geschichte", Bonn, 1977, pp. 42-66.

${ }^{100}$ La obra de síntesis que mejor plasma este modelo historiográfico es la de H. PLANITZ, Die deutsche Stadt des Mittelalters. Von der Römerzeit bis zu den Zunftkämpfen, Graz-Colonia, 1954.

${ }^{101}$ Vid. Knut SCHULZ, Die Ministerialität als Problem der Stadtgeschichte. Einige allgemeine Bemerkungen, erläutert am Beispiel der Stadt Worms, "Rheinische Vierteljahrsblätter", 32 (1968), pp. 184-219.
} 
llegaron a alcanzar una posición sociopolítica superior a la de amplios sectores de la población considerada formalmente libre, incluidos los mercaderes. Y por este motivo el historiador Karl Bosl acuñó en su día para calificar su posición el concepto de adelige Unfreiheit (servidumbre noble) ${ }^{102}$. Esta circunstancia facilitó la puesta en marcha en el transcurso de los siglos XII y XIII de un proceso de asimilación de los ministeriales a la baja nobleza a través de la caballería, y gracias a que se les terminó reconociendo la capacidad de recibir feudos de sus señores, que en origen había estado reservada a los nobles de condición libre ${ }^{103}$. Los historiadores, sin embargo, tradicionalmente sólo habían considerado posible este ascenso de los ministeriales a la baja nobleza en los ámbitos rurales, porque partían del presupuesto de que en las ciudades los ministeriales representaban un elemento extraño que por fuerza debía desaparecer a partir del momento en que éstas alcanzaban la plena autonomía frente a sus señores y se consolidaban desde el punto de vista sociopolítico como comunidades juramentadas, inspiradas por principios de carácter consociativo, que aseguraba a todos sus miembros los mismos derechos y obligaciones ${ }^{104}$. Estudios más recientes han conseguido demostrar, sin embargo, que en muchas ciudades los ministeriales, lejos de abandonarlas conforme éstas iban liberándose del dominio señorial, consiguieron integrarse en sus grupos dominantes y asegurarse incluso posiciones de máxima influencia en su seno. No obstante, los autores fieles al tradicional modelo interpretativo, sin negar la evidencia del predominio de familias de origen ministerial en los grupos dirigentes de numerosas ciudades alemanas, han persistido en calificar a este estamento como un elemento extraño a las estructuras sociopolíticas urbanas del Imperio alemán, y sostienen por ello que todos aquellos individuos de origen ministerial que terminaron integrándose en las sociedades urbanas lo hicieron gracias a haberse asimilado al estamento burgués, que tendría su origen en las comunidades juramentadas de mercaderes libres, en las que luego se fueron integrando otros sectores sociales, conforme avanzó el proceso de uniformización jurídica de la población urbana ${ }^{105}$. Y estas reticencias a admitir que los ministeriales lograsen reservarse un puesto en las estructuras sociopolíticas urbanas, que les garantizase durante un prolongado período de tiempo la preservación de sus privilegios estamentales, ha llevado a algunos autores incluso a negar el origen ministerial de determinados individuos o grupos que

\footnotetext{
${ }^{102}$ Kart BoSL, Die Reichsministerialität der Salier und Staufer, Stuttgart, 1950 y 1951, 2 vols. Y Die adelige Unfreiheit, en F.L. WAGNER (Ed.), Ministerialität im Pfalzer Raum, Speyer, 1975, pp. 9-19.

${ }^{103}$ Vid. Joseph FLECKENSTEIN, Die Entstehung des niederen Adels und das Rittertum, en Joseph FLECKENSTEIN (Ed.), Herrschaft und Stand. Untersuchungen zur Sozialgeschichte im 13. Jahrhundert, Göttingen, 1977, pp. 17-39. Y Karl BosL, Die adelige Unfreiheit. cit.

${ }^{104}$ Ésta es la tesis que se mantiene en la obra clásica de H. PlaniTZ, Die deutsche Stadt,

${ }^{105}$ Este punto de vista ha sido defendido por J. FLECKENSTEIN, Die Problematik von Ministerialität und Stadt im Spiegel Freiburger und Strassburger Quellen, en E. MASCHKE y J. SYDOW (Eds.), Stadt und Ministerialität, Stuttgart, 1973, pp. T-15. YY, Ministerialität und Stadtherrschaft. Ein Beitrag zu ihrem Verhältnis am Beispiel von Hildesheim und Braunschweig, en "Festschrift für Helmut Beumann zum 65. Geburtstag", Sigmaringen, 1977, pp. 349-364.
} 
en distintas ciudades alemanas son identificados expresamente en los documentos del siglo XIII como caballeros ${ }^{106}$. En efecto, la asunción de la tesis clásica que consideraba que los comunidades urbanas autónomas de la Alemania plenomedieval eran obra de comunidades juramentadas, inspiradas por mercaderes libres, ha llevado a minusvalorar durante mucho tiempo la presencia de elementos nobles en estas ciudades, y a negar la existencia de cualquier tipo de vinculación entre los ministeriales y los que a partir del siglo XIII aparecen identificados en los documentos como caballeros, respecto de los cuales se ha mantenido la tesis de que se trataba de simples burgueses ennoblecidos. Numerosos trabajos acometidos en las últimas décadas han permitido comprobar, sin embargo, que amplios sectores de los grupos oligárquicos de muchas e importantes ciudades imperiales y libres procedían de familias de origen ministerial. Así se ha demostrado en concreto en monografías dedicadas a ciudades que en origen fueron de señorío episcopal, como Colonia, Tréveris, Worms, Estrasburgo, Ratisbona, Maguncia o Coblenza $^{107}$. Y también en otras centradas en el estudio de ciudades del señorío regio que se terminaron consolidando como ciudades imperiales, como Nürnberg, Francfort del Meno y varias más ${ }^{108}$.

La posición de los individuos nobles de origen ministerial en el seno de las comunidades políticas urbanas, sobre todo en aquellas ciudades que habían estado en origen sometidas a señorío episcopal, no dejaba de estar exenta de contradicciones, por cuanto muchos de ellos continuaron mantenien-

${ }^{106}$ Así lo hace S. WILKE al referirse a los caballeros de Goslar en el siglo XIII, en Das Goslarer Reichsgebiet und seine Beziehungen zu den territorialen Nachbargewalten, Max Planck Institut Göttingen, 1971. Critica su punto de vista W. PETKE, Pfalzstadt und Reichsministerialität. Uber einen neuen Beitrag zur Reichsgut- und Pfalzenforschung, "Blätter für deutsche Landesgeschichte" (1973), pp. 300 y ss. También Ph. DOLLINGER muestra reticencias a buscar el origen de los patriciados nobles de las ciudades altorrenanas del siglo XIII en los ministeriales. Vid. su trabajo Das Patriziat der oberrheinischen Städte und seine inneren Kämpfe in der ersten Hälfte des 14. Jahrhunderts, en H. STOOB (Ed.) Altständisches Bürgertum, vol. II, Darmstadt, 1978 , pp. 198-9. Critica su punto de vista en relación a la cludad de Estrasburgo, H. MOSBACHER, Kammerhandwerk, Ministerialität und Bürgertum in Strassburg. Studien zur Zusammensetzung und Entwicklung des Patriziats im13. Jahrhundert, "Zeitschrift für die Geschichte des Oberrheins", 119 (1971), pp. 158 y ss.

${ }^{107}$ Sobre Colonia Vid. K. SCHULZ, Richerzeche, Meliorat und Ministerialität in Köln, en H. STEHKÄMPER (Ed.) Köln, Das Reich und Europa, Köln, 1971, pp. 149-172. Sobre Tréveris, K. SCHULZ, Ministerialität und Bürgertum in Trier. Untersuchungen zur rechtlichen und sozialen Gliederung der Trierer Bürgerschaft vom ausgehenden 11. bis zum Ende des 14. Jahrhunderts, Bonn, 1968. Sobre Worms K. SCHULZ, Die Ministerialität als Problem, cit. Sobre Estrasburgo, H. MOSBACHER, Kammerhandwerk, cit. Sobre Ratisbona, Karl BosL, Die Sozialstruktur der mittelalterlichen Residenz- und Fernhandelstadt Rengensburg. Die Entwicklung ihres Bürgertums vom 9.-14. Jahrhundert, en Th. MAYER (Ed.), Untersuchungen zur gesellschaftlichen Struktur der mittelalterlichen Städte in Europa (Reichenau Vorțäge), Konstanz- Stuttgart, 1966, pp. 93213. Sobre la integración de caballeros de origen ministerial en el grupo dirigente de Coblenza, y el destacado papel que las familias nobles desempeñaron en el gobierno urbano vid. Tadeusz ROSLANOWSKI, Recherches sur la vie urbaine et en particulier sur le patriciat dans les villes de la moyenne Rhénanie septentrionale (Fin du XIe-début du XIVe. siècles), Varsovia, 1964, pp. 97 y ss. Y F. MICHEL, Der Koblenzer Stadtadel im Mittelalter, "Mitteilungen der westdeutschen Gesellschaft für Familienkunde", 16 (1952), pp. 1-20.

${ }^{108}$ Vid. A. SCHLUNK, Stadt ohne Bürger?. Eine Untersuchung über die Führungsschichten der Städte Nürnberg, Altenburg und Frankfurt um die Mitte des 13. Jahrhunderts, en U. BERTMANN, F. IRSIGLER y J. SCHNEIDER (Eds.), Hochfinanz. Wirtschaftsräume. Innovationen, "Festschrift für Wolfgang von Stromer", vol. I, Treveris, 1987. Y. H.F. FRIEDERICHS, Herkunft und ständische Zuordnung des Patriziats der wetterauischen Reichsstädte bis zum Ende des Staufertums, "Hessisches Jahrbuch für Landesgeschichte", 9 (1959), pp. 37-75. Sobre la ciudad de Goslar, Vid. W. PETKE, art. cit. 
do estrechos vínculos de carácter feudo-vasallático con los obispos que habían ejercido con anterioridad el señorío sobre la ciudad en que habían fijado su residencia. Y las obligaciones que de ello se derivaban para ellos entraban frecuentemente en contradicción con las que habían contraído con la sociedad política urbana en la que habían pasado a integrarse ${ }^{109}$. Por este motivo, con relativa frecuencia, determinados sectores de las oligarquías urbanas con fuertes inclinaciones pronobiliarias optaron por romper los lazos de fidelidad hacia el sistema urbano para integrarse en el estamento de la pequeña nobleza rural, como ocurrió, por ejemplo, en repetidas ocasiones en Estrasburgo a lo largo de los siglos XIV y XV ${ }^{10}$.

En cualquier caso, fueron preferentemente los ministeriales de más alto rango los que con más dificultades tropezaron para integrarse en las comunidades políticas urbanas cuando éstas se liberaron de la tutela señorial, y por ello optaron por trasladarse al campo. Así podemos comprobarlo mediante el análisis de lo ocurrido en Estrasburgo a partir del año 1263, cuando la ciudad alcanzó la plena autonomía frente al poder episcopal. Según el punto de vista tradicional, en aquel momento todos los ministeriales que habían estado al servicio del obispo abandonaron la ciudad, en seguimiento de su señor. Pero más recientemente $\mathrm{H}$. Mosbacher ha demostrado que sólo fueron los de más alto rango los que entonces marcharon, mientras que el resto permanecieron, integrándose en la comunidad política urbana, y pasaron a adoptar el título de milites, que hasta entonces había estado reservado a los ministeriales mayores ${ }^{111}$. Por su parte, también en la ciudad de señorío regio de Francfort del Meno nos consta que a comienzos del reinado de Rodolfo I seis ministeriales imperiales la abandonaron para construir en sus cercanías el castillo de Rödelheim y ponerse allí al servicio del rey, desapareciendo a raíz de ello sus nombres de las listas de testigos en los documentos concejiles, donde en adelante ya no se vuelven a encontrar menciones a milites ${ }^{112}$.

Dejando, pues, a un lado a estos ministeriales de alto rango, la mayoría permanecieron en las ciudades, e incluso recibieron todo tipo de facilidades para poder fundirse con los demás grupos sociales urbanos. Así, Thomas Martin interpreta la concesión de privilegios por Rodolfo I a múltiples ciudades, en los que se reconocía a sus vecinos la capacidad para recibir feudos, hasta entonces restringida a los miembros de la nobleza y a los ministeriales, como una medida orientada a favorecer la fusión entre caballeros con residencia urbana y burgueses ${ }^{113}$. Y precisamente esta capacidad de recibir feudos (Lehensfähigkeit) reconocida a los vecinos de las ciudades

\footnotetext{
${ }^{109}$ Utilizando ejemplos tomados en su mayor parte del siglo XIV ilustra muy bien esta problemática la obra de M. ALIOTH, Gruppen an der Macht. Zunfte und Patriziat in Strassburg im 14. und 15. Jahrhundert. Untersuchungen zu Verfassung, Wirtschaftsgefüge und Sozialstruktur, vol. I, Basilea-Frankfurt, 1988, pp. 222 y ss.

${ }^{110}$ Vid. M. Alioth, op. cit.

${ }^{111}$ Vid. H. MOSBACHER, Kammerhandwerk, cit.

${ }^{112}$ F. SCHWIND, Die Landvogtei in der Wetterau, Marburg, 1972, p. 110.

${ }^{113}$ Th. MARTín, Die Städtepolitik Rudolfs von Habsburg, Göttingen, 1976, pp. 142-3.
} 
ha sido interpretada por muchos autores como prueba de que en el Imperio las fronteras estamentales entre ciudades y campo no fueron en principio insalvables, y de que derecho urbano y derecho feudal no se excluían mutuamente ${ }^{114}$.

Para K. Schulz, por el contrario, el reconocimiento de la capacidad para recibir feudos quedó restringido inicialmente entre los vecinos de las ciudades a los ministeriales. Y, por otra parte, este mismo autor ha restado importancia a las concesiones de privilegios de Lehensfähigkeit al conjunto de los vecinos de determinados núcleos urbanos, por considerar que se trató de un fenómeno tardío, que no supuso ninguna amenaza real para la posición privilegiada que en dichos núcleos habían alcanzado en momentos anteriores los ministeriales. Y, en esta misma línea, algunos otros autores han destacado también que en la mayor parte de los casos los privilegios de Lehensfähigkeit concedidos a ciudades tuvieron un alcance limitado y no permitieron que se diese una equiparación total a este respecto entre individuos de origen ciudadano y miembros de la pequeña nobleza, ya fuesen éstos de origen libre o ministerial ${ }^{15}$.

El desacuerdo fundamental entre los investigadores se plantea, por tanto, en torno a si los caballeros avecindados en las ciudades del siglo XIII eran descendientes de ministeriales o, por el contrario, representantes de una nueva nobleza aparecida en dichas ciudades como consecuencia de la inmigración de caballeros procedentes del campo, con los cuales habrían tendido a fundirse representantes de la burguesía atraídos por el señuelo de la caballería y dotados de privilegios regios que les facultaban para recibir feudos, antes sólo accesibles para la nobleza y los ministeriales.

No estamos en condiciones de entrar a terciar en este debate, determinando de forma categórica a quién asiste la razón. En cualquier caso consideramos que se han de evitar las generalizaciones, pues dentro de las ciudades alemanas se dieron situaciones muy diversas. Hubo algunas, como Estrasburgo, en que el peso de los elementos nobles heredados del pasado señorial fue mayor y se prolongó durante más tiempo, mientras que en otras la exclusión radical de estos elementos tuvo lugar en una fase muy temprana. Es lo que ocurrió, por ejemplo, en Friedberg, donde los caballeros descendientes de los antiguos ministeriales imperiales al servicio de los Staufer no se integraron en la comunidad política urbana, sino que, por el contrario, pasaron a constituir una corporación autónoma con sede en el castillo imperial contiguo a la ciudad. A partir de entonces los conflictos entre la referida corporación de caballeros del castillo de Friedberg y los vecinos de la ciudad fueron constantes, durante la segunda mitad del siglo XIII y el siglo XIV,

\footnotetext{
${ }^{114}$ Vid. O. BRUNNER, Bürgertum und Feudalwelt in der europäischen Sozialgeschichte, en C. HAASE (Ed.), Die Stadt des Mittealters, cit., vol. 3, Darmstadt, 1969, pp. 496 y ss. También recalca la compatibilidad de derecho feudal y derecho urbano J. FLECKENSTEIN, Die Problematik, cit. p. 9.

${ }^{115} \mathrm{H}$. LIEBERICH, Rittermässigkeit und bürgerliche Gleichheit. Anmerkungen zur gesellschaftlichen Stellung des Bürgers im Mittelalter, "Festschrift für Hermann Krause", Colonia-Viena, 1975 , pp. $78-9$.
} 
hasta que finalmente la corporación obtuvo por cesión del Imperio el señorío sobre la ciudad, que como consecuencia perdió de forma definitiva su autonomía ${ }^{116}$.

Entre estas situaciones extremas se dieron otras muchas de muy variado signo, en función del grado de privilegio que lograron mantener los descendientes de los antiguos ministeriales, que fue mayor en ciudades como Basilea o Maguncia ${ }^{117}$, que en otras como Colonia, donde, a pesar de ello, también llegó a consolidarse un patriciado con claros rasgos nobiliarios, como el combate a caballo, la afición por los torneos o la posesión de feudos ${ }^{118}$, que, sin embargo, no pueden explicarse como resultado de su origen ministerial ${ }^{119}$.

Al margen, en cualquier caso, de cuál fuera su origen, el hecho incuestionable es que en muchas ciudades del Imperio al norte de los Alpes se desarrolló en los siglos plenomedievales una nobleza urbana integrada por individuos expresamente identificados en los documentos como caballeros ${ }^{120}$. Este grupo no llegó a ocupar, sin embargo, en ellas una posición de dominio similar a la alcanzada por la nobleza en las ciudades castellanas bajomedievales, sino que en todo momento tuvo que compartir el poder con otros grupos sociales ${ }^{121}$, que fueron los que a largo plazo terminaron imponiéndose. Se trató, por consiguiente, de un grupo en cierto modo marginal, y que con el transcurso del tiempo se fue progresivamente debilitando hasta terminar por desaparecer en el transcurso de los siglos bajomedievales de prácticamente

\footnotetext{
${ }^{116}$ Th. SCHILP, Die Reichsburg Friedberg im Mittelalter. Untersuchungen zu ihrer Verfassung, Verwaltung und Politik, Friedberg/Hessen, 1982. Vid. También las referencias que hacemos al caso de Friedberg en Máximo DIAGO HERNANDO, El papel de los castillos, cit.

${ }^{117}$ Sobre el alcance de los privilegios estamentales de los patriciados de origen ministerial de Maguncia y Basilea Vid. K. ScHULZ, Die Ministerialität in rheinischen Bischofsstädten, en E. MASCHKE y J. SYDOW (Eds.), Stadt und Ministerialität, cit., pp. 17-39.

${ }^{118}$ Destaca los rasgos nobiliarios del patriciado de Colonia, que controló el gobierno de la ciudad hasta 1396, K. MILITZER, Ursachen und Folgen der innerstädtischen Auseinandersetzungen in Köln in der zweiten Hälfte des 14. Jahrhunderts, Colonia, 1980. IDEM, Führungsschicht und Gemeinde in Köln im 14. Jahrhundert, en Wilfried EHBRECHT (Ed.), Städtische Führungsgruppen und Gemeinde in der werdenden Neuzeit, Colonia-Viena, 1980, pp. 11-24. Vid. tambien W. HERBORN, Bürgerliches Selbstverständnis im spätmittelalterlichen Köln. Bemerkungen zu zwei Hausbüchern aus der ersten Hälfte des 15. Jahrhunderts", en Die Stadt in der europäischen Geschichte, "Festschrift Edith Ennen", Bonn, 1972, pp. 490-520. Y Th. ZOTZ, Städtisches Rittertum und Bürgertum in Köln um 1200, en Institutionen, Kultur und Gesellschaft im Mittelalter, "Festschrift für Josef Fleckenstein", Sigmaringen, 1984, pp. 609-38.

${ }^{119}$ Defiende la tesis de que en el patriciado de Colonia dominó el elemento mercantil frente al ministerial Luise von WINTERFELD, Handel, Kapital und Patriziat in Köln bis 1400, Lübeck, 1925.

${ }^{120}$ Vid. Knut SCHULZ, Nobiltà urbana e borghesia specialmente nelle città della Germania meridionale (secolo XV), en R. ELZE y G. FASOLI, Aristocrazia cittadina e ceti popolari nel tardo Medioevo in Italia e in Germania, Bologna, 1984, pp. 223-53.

${ }^{121}$ En varias ciudades del Alto Rhin se estableció un régimen de reparto de oficios de gobierno entre caballeros y ciudadanos, que garantizaba a estos últimos una mayor presencia en la principal institución de gobierno local. Assí, en Worms desde 1233 fueron asignados a los caballeros seis puestos en el consejo municipal (Rat), y nueve a los ciudadanos. En Basilea cuatro correspondieron a los caballeros y ocho a los ciudadanos. En Estrasburgo, después de 1334, hubo en el Rat ocho caballeros, catorce ciudadanos y veinticinco representantes de los artesanos. Parecida distribución de asientos se contempló en Zürich desde 1336. Por fin, en Friburgo de Brisgovia desde 1293 en el Rat había ocho caballeros, ocho mercaderes y ocho artesanos. Vid. Knut SCHULZ, Patriziergesellschaften und Zünfte in den mittel- und oberrheinischen Bischofsstädten", en Berent SCHWINEKÖPER (Ed.), Gilden und Zünfte. Kaufmännische und gewerbliche Genossenschaften im frühen und hohen Mittelalter, Sigmaringen, 1985, p. 316.
} 
todas las ciudades en que había alcanzado cierto desarrollo, como trataremos de demostrar a continuación.

\section{Decadencia y desaparición de la nobleza urbana en el Imperio durante el período bajomedieval}

Uno de los ámbitos del Imperio donde más fuerza alcanzó la nobleza urbana, y donde durante más tiempo pervivió, fue el del Alto Rhin. Por ello, desde la perspectiva de la reconstrucción del proceso de decadencia de este grupo sociopolítico en el período bajomedieval, ofrece particular interés centrarse en el análisis de este espacio.

Como demostró en su momento el profesor Dollinger, fue un rasgo característico de varias de sus principales ciudades, entre las que cabe destacar Estrasburgo y Basilea, el hecho de contar con un patriciado "dúplice", constituido por dos grupos, uno integrado por nobles y otro por ciudadanos. De esta división se derivaron, no obstante, según este autor, constantes conflictos entre los dos grupos, que contribuyeron a su debilitamiento, y favorecieron en contrapartida el auge de los gremios, en los que tanto los patricios nobles como los ciudadanos buscaron apoyo para imponerse a sus rivales $^{122}$.

Por su parte, al progresivo debilitamiento del patriciado noble también contribuyó en notable medida el hecho de que muchos de sus miembros mantuvieron una posición contradictoria, pues, mientras por un lado estaban integrados en una comunidad política urbana, por otro debían fidelidad, en virtud de los vínculos vasalláticos concertados, a príncipes y nobles, tanto laicos como eclesiásticos, que se contaban entre los principales enemigos de la ciudad donde estaban avecindados ${ }^{123}$.

Por fin, los factores económicos también tuvieron su parte de responsabilidad en este proceso de debilitamiento, al provocar un progresivo desplazamiento de los nobles rentistas por individuos más emprendedores procedentes de otros grupos sociales, dedicados al comercio y a las finanzas, como algunos investigadores han constatado que ocurrió tanto en Estrasburgo ${ }^{124}$ como en Zürich ${ }^{125}$.

A los patriciados de marcado perfil nobiliario constituidos por descendientes de ministeriales se les ha atribuido con frecuencia, en efecto, una notable falta de dinamismo en el terreno económico que, a juicio de

\footnotetext{
${ }^{122} \mathrm{Ph}$. Dollinger, Das Patriziat, cit., pp. 200 y ss.

${ }^{123} \mathrm{La}$ especial incidencia de este factor en Estrasburgo es resaltada por M. ALIOTH, op. cit. pp. 222 y sS.

${ }^{124}$ M. Alioth, op. cit., pp. 239 y ss. Sostiene este autor que el patriciado rentista se vio afectado por problemas económicos cada vez más graves conforme avanzó el siglo XIV, mientras que el grupo al que denomina "coalición comercial" se enriquecía progresivamente.

${ }^{125}$ Vid. U. SCHLUER, Untersuchungen ubre die soziale Struktur von Stadt und Landschaft Zürich im fünfzehnten Jahrhundert, Zürich, 1978 pp. 51 y ss. Y $\mathrm{H}$. AMMAN über die Wirtschaftsstellung Zürichs im ausgehenden Mittelalter, "Zeitschrift für schweizerische Geschichte", 30 (1950), pp. 530-67.
} 
determinados autores, habría sido la principal responsable de su decandencia en el período bajomedieval, ante el empuje de los nuevos patriciados integrados por prósperos mercaderes y financieros. Es la tesis que defienden, por ejemplo, Karl Bosl en su estudio sobre la ciudad de Ratisbona ${ }^{126}$, o Klaus Militzer en su análisis de la caída en 1396 del patriciado de Colonia ${ }^{127}$.

El desplazamiento de los patriciados nobles, de origen ministerial, de los órganos de gobierno urbano se llevó a cabo en bastantes ciudades del Imperio en el transcurso del siglo XIV mediante la implantación de modelos institucionales que contemplaban a los gremios como mecanismo fundamental para la regulación del acceso al ejercicio del poder. A este respecto se ha de destacar que algunas de las ciudades en las que en el siglo XIII el patriciado noble de origen ministerial había alcanzado un mayor desarrollo, como Basilea o Estrasburgo, destacaron después en el conjunto del Imperio por ser las que adoptaron modelos constitucionales de gobierno de más marcada impronta gremial ${ }^{128}$. Y, por contraste, otras ciudades del norte que, desde el primer momento habían contemplado la radical exclusión de los nobles de la sociedad política local, como Hamburgo o Lübeck, no llegaron a admitir la participación de los gremios en los procesos de regulación del acceso al ejercicio del poder hasta el siglo XIX ${ }^{129}$.

No obstante, la decadencia de los patriciados nobles en las ciudades alemanas durante el siglo XIV no cabe explicarla exclusivamente como una consecuencia de la irrupción de los gremios en la escena política ${ }^{130}$. De hecho esta irrupción afectó en igual medida a los patriciados con fuerte componente nobiliario, constituidos mayoritariamente por terratenientes descendientes de ministeriales, que a los que tenían un perfil más burgués. Y, por otro lado, aunque ciertamente se dieron situaciones extremas, en que la implantación de

\footnotetext{
${ }^{126}$ Karl BosL, Die Sozialstruktur, cit. Utiliza este autor los conceptos de Verwaltungspatriziat y Handelspatriziat, e interpreta la revuelta que tuvo lugar en esta ciudad en 1334 (Aueraufstand) como victoria de este segundo patriciado mercantil frente al primero (pp. 195-6). Al grupo victorioso le caracterizaria, segun este autor, el dinamismo económico en el comercio y las finanzas, mientras que el vencido integraría preferentemente a descendientes de ministeriales, que debían su posición económica a la posesión de tierras y al desempeño de oficios al servicio de los obispos.

${ }^{127}$ Klaus MILITZER, Ursachen und Folgen, cit. y Führungsschicht und Gemeinde in Köln im 14. Jahrhundert, en W. EHBRECHT (Ed), Städtische Führungsgruppen und Gemeinde in der werdenden Neuzeit, Colonia-Viena, 1980, pp. 11-24.

${ }^{128}$ Sobre el régimen de gobierno gremial en Basilea Vid. H. FÜEGLISTER, Handwerksregiment. Untersuchungen und Materialien zur sozialen und politischen Struktur der Stadt Basel in der ersten Hälfte des 16. Jahrhunderts, Basilea-Frankfurt, 1981. Sobre el de Estrasburgo Vid. K. SCHULZ, Handwerksgesellen und Lohnarbeiter. Untersuchungen zur oberrheinischen und oberdeutschen Stadtgeschichte des 14. bis 17. Jahrhunderts, Sigmaringen, 1985, pp. 14 y ss.

${ }^{129}$ Sobre Hamburgo Vid. O. BRUNNER, Hamburg und Wien. Versuch eines sozialgeschichtlichen Vergleichs, en Neue Wege der Verfassungs- und Sozialgeschichte, Göttingen, 1968, pp. 326 y SS. Y sobre Lübeck, A. von BRANDT, Die gesellschaftliche Struktur der mittelalterlichen Lübeck, en Th. MAYER'(Ed.), Untersuchungen, cit., pp. 215-39.

${ }^{130}$ Sobre este proceso, al que la historiografía en lengua alemana se refiere con el término de Zunftkämpfe (luchas de los gremios), existe una abundante bibliografía. Entre otras muchas obras interesan K. CZOK, Die Bürgerkämpfe in Süd- und Westdeutschland im 14. Jahrhundert, en C. HAASE (Ed.), Die Stadt des Mittelalters, cit. vol. 3, Darmstadt, 1973, pp. 303-44. Y E. MASCHKE, Verfassung und soziale Kräfte in der deutschen Stadt des spaten Mittelalters, vornehmlich in Oberdeutschland, "Vierteljahrschrift für Sozial- und Wirtschaftsgeschichte", 46 (1959), pp. 289-349 y 433-476.
} 
la constitución gremial conllevó la radical exclusión del ejercicio del poder de los miembros del patriciado que hasta entonces lo habían controlado en régimen de monopolio, como ocurrió en Colonia en $1396^{131}$, lo más habitual fue que tras las revueltas gremiales, y las modificaciones de las constituciones políticas urbanas que las mismas propiciaron, las familias de los antiguos patriciados pasasen a compatir el ejercicio del poder con las nuevas familias que controlaban los gremios, según puso de manifiesto en su día Erich Maschke, aportando numerosos ejemplos ilustrativos ${ }^{132}$.

El proceso de decadencia de los patriciados nobles en aquellas ciudades en que este grupo había alcanzado cierto desarrollo en los siglos plenomedievales tuvo habitualmente un carácter gradual, de larga y lenta agonía, con el resultado final de su plena desaparición. Y con frecuencia no se tradujo en bruscas modificaciones del modelo constitucional vigente, como nos pone de manifiesto el caso de Nördlingen, donde hacia mediados del siglo XIV el patriciado de origen ministerial, poseedor de tierras, fue siendo poco a poco reemplazado por familias volcadas hacia la actividad mercantil, sin que se introdujesen modificaciones en el modelo institucional que regulaba el acceso al ejercicio del poder en la ciudad ${ }^{133}$.

En otras ciudades la desaparición del grupo fue el resultado de una ininterrumpida sangría, causada por el abandono por parte de los caballeros descendientes de ministeriales de sus residencias urbanas para proceder a instalarse en sus feudos del campo. Así ocurrió, por ejemplo, en Estrasburgo, donde, según Martin Alioth, tuvo lugar en el transcurso del período bajomedieval un continuado goteo de individuos situados en la cúspide de la pirámide social de la ciudad, que la abandonaban para incorporarse a la nobleza rural, poniéndose al servicio del obispo o de otros nobles del entorno $^{134}$. Estas deserciones contribuyeron decisivamente al debilitamiento del grupo del patriciado noble en esta capital renana, que, no obstante, ofreció fuerte resistencia a ser desplazado de la posición de dominio que en un primer momento había logrado ocupar, como bien demuestran episodios del tipo de la guerra de Dachstein de 1419-20. Y otro tanto cabe decir del patriciado noble de la ciudad de Basilea, que también destacó por la forma violenta en que se resistió a terminar siendo totalmente desplazado de su inicial posición hegemónica ${ }^{135}$.

Estas ciudades del Alto Rhin, que fueron las que contaron con patriciados nobles más consistentes y poderosos, destacaron también por ser

\footnotetext{
${ }^{131}$ Vid. Klaus MILITZER, Ursachen, cit. y Führungsschicht, cit. Vid. también W. HERBORN, Die politische Führungsschicht der Stadt Köln im Spatmittelalter, Bonn, 1977.

${ }^{132} \mathrm{E}$. MASCHKE, Verfassung und soziale Kräfte, cit.

${ }^{133}$ Vid. R. KIESSLING, Die Stadt und ihr Land, Colonia-Viena, 1989, pp. 152-6. Este autor utiliza también los conceptos de Verwaltungspatriziat y Handelspatriziat, propuestos por Karl Bosl.

${ }^{134}$ M. Alioth, op. cit., p. 241.

${ }^{135}$ Sobre la guerra de Dachstein de 1419-20 vid. M. ALIOTH, op. cit. Sobre la reacción del patriciado noble de Basilea en las primeras décadas del siglo $X V$ aporta algunas noticias $\mathrm{K}$. SCHULZ, Handwerksgesellen, cit., pp. 20-1 (nota 93).
} 
las que durante más tiempo mantuvieron unas estructuras sociopolíticas marcadas por la presencia del elemento noble en el seno de la comunidad política urbana. Pero también en ellas éste terminó por desaparecer, ante el empuje de otros grupos sociales, de modo que, por ejemplo en Basilea el gobierno terminó quedando plenamente en manos de los gremios ${ }^{136}$. Y consiguientemente en el siglo XV ya no cabe hablar de la persistencia de nobleza urbana propiamente dicha en las ciudades del Imperio.

Ciertamente en muchas de estas ciudades, como reacción ante el avance político de los gremios, se consolidaron patriciados bastante herméticos, que con frecuencia adoptaron modos de vida muy próximos a los propios de la nobleza rural, como demuestra por ejemplo su afición a la celebración de torneos y el hecho de que sus miembros combatiesen a caballo ${ }^{137}$. Pero, a pesar de ello, los miembros de estos patriciados, ni siquiera de los más exclusivistas, como lo fue, por ejemplo, el de Nürnberg, llegaron a ser reconocidos como iguales por los nobles asentados en el campo, que los excluyeron de forma sistemática de sus corporaciones. A este respecto se ha de tener muy en cuenta que el fuerte arraigo en las ciudades alemanas del principio consociativo (genossenschaftlich) supuso un fuerte freno para el desarrollo de grupos oligárquicos de perfil nobiliario, al favorecer las formas colegiadas de ejercicio del poder frente a las de tipo decididamente personalista propias de la nobleza. De hecho fueron los propios miembros de las oligarquías los que se opusieron a que se estableciesen entre ellos diferencias formales de rango como consecuencia de la obtención por algunos de privilegios de nobleza ${ }^{138}$. Ciertamente en casos excepcionales, como, por ejemplo, el de la ciudad de Nürnberg, todos los miembros del patriciado en su conjunto llegaron a obtener de la autoridad imperial privilegios que les autorizaban a ostentar predicados de nobleza, que les diferenciaban formalmente del resto de la población urbana ${ }^{139}$. Pero se trataba de distinciones de carácter meramente formal, que en ningún caso propiciaron una equiparación efectiva con los miembros del estamento noble, que siempre consideraron como de inferior rango a los miembros de los patriciados urbanos, incluído

\footnotetext{
${ }^{136}$ Vid. H. FÜEGLISTER, Handwerksregiment, cit.

${ }^{137}$ Entre las obras que destacan la tendencia al ennoblecimiento de ciertos patriciados alemanes de los siglos XV y XVI cabe mencionar la de R. KIESSLING, Die Stadt und ihr Land, Para diferenciar entre la burguesía ennoblecida del siglo XV y la antigua nobleza urbana de origen ministerial, este autor acuña, no obstante, el concepto de "sekundäre Aristokratisierung", es decir "aristocratización secundaria" a la hora de referirse al proceso que tuvo lugar en el siglo $\mathrm{XV}$. También, refiriéndose al caso concreto de Zürich, diferencia entre nobleza viẹja y burguesía ennoblecida, que sólo gozaba de reconocimiento social pero de ningún privilegio político, U. SCHLÜER, Untersuchungen über die soziale Struktur von Stadt und Landschaft Zürich im fünfzehnten Jahrhundert, Zürich, 1978, pp. 166-174.

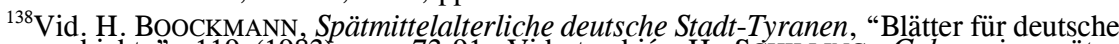
Landesgeschichte" 119 (1983), pp. 73-91. Vid. también H. SCHILLING, Gab es im späten Mittelater und zu Beginn der Neuzeit in Deutschland einen städtischen "Republikanismus"?, en H. KÖNIGSBERGER (Ed.), Republiken und Republikanismus im Europa der Frühen Neuzeit, Múnich, 1988, pp. 101-44.

${ }^{139}$ Vid. H.H. HofMANN, Nobiles Norimbergenses. Beobachtungen zur Struktur der reichsstädtischen Oberschicht, en Th. MAYER, Untersuchungen, cit., pp. 53-92. Y G. HIRSCHMANN, Das Nürnberger Patriziat, en R. RösSLER (Ed.), Deutsches Patriziat 1430-1740, Limburg/Lahn, 1968, pp. 257-76.
} 
el de Nürnberg ${ }^{140}$, aunque, lógicamente, sí se mostraron más predispuestos a entablar relaciones sociales con las familias pertenecientes a los patriciados de aquellas ciudades que tenían un carácter mas exclusivista, como eran, además del de Nürnberg, los de Estrasburgo, Augsburgo y Ulm, dentro del ámbito de la Alta Alemania, que es donde mayor desarrollo alcanzaron las corporaciones de pequeña nobleza rural, integradas por los llamados "caballeros imperiales" $(\text { Reichsritter })^{141}$. Pero incluso las familias pertenecientes a los patriciados de estas ciudades tropezaron con insalvables dificultades para ser reconocidas como de igual rango por las corporaciones de la nobleza rural. Y una buena prueba de ello nos la proporciona la constatación del veto que se les impuso a sus miembros a la entrada en los cabildos de las principales ciudades alemanas, incluido el de Augsburgo, donde en el siglo XV la familia Welser, pese a su enorme riqueza e influencia, tropezó con una encarnizada resistencia del cabildo catedralicio, integrado todo él por individuos de origen noble, a admitir como canónigo a uno de sus miembros, por su origen burgués, que desencadenó un prolongado litigio en la Corte pontificia ${ }^{142}$.

La fuerza de los principios de carácter consociativo, propiciadores de un régimen de ejercicio colegiado del poder, en las constituciones políticas de las ciudades del Imperio, y la vigencia en ellas del principio de igualdad jurídica de todos los vecinos, con independencia de su posición socioeconómi$\mathrm{ca}^{143}$, impidieron la conversión de sus grupos patricios en corporaciones nobles privilegiadas respecto del resto de la población urbana. Así nos lo corrobora, en concreto, el análisis de la posición que en estas ciudades ocuparon aquéllos de sus vecinos que eran a la vez señores de vasallos. Ciertamente no se dio con frecuencia en el Imperio el caso de que ciudadanos fuesen a la vez señores de vasallos, pero ambas condiciones no se consideraron tampoco en principio incompatibles. Y de hecho, a lo largo del período bajomedieval, no fueron pocos los vecinos de ciudades que, mediante compras efectuadas a nobles en dificultades económicas, llegaron a hacerse con el control de señoríos. Las instituciones de gobierno de las ciudades de las que éstos eran vecinos, tendieron, sin embargo, a obligarles a que colocasen dichos señoríos bajo su tutela, y les reconociesen la capacidad de tratar a sus habitantes como si fuesen vasallos directos de la propia ciudad, cobrándoles

\footnotetext{
${ }^{140}$ En el caso del patriciado de Nürnberg sólo a partir de finales del siglo XVII, por virtud de unos privilegios de 1696 y 1697 , pudieron las familias que formaban parte del mismo incorporarse a las corporaciones de baja nobleza imperial (Reichstitterschafț) sin renunciar a su condición de ciudadanos, aunque si deseaban desempeñar algún tipo de oficio de los reservados para los miembros de tales corporaciones sí estaban obligados a renunciar a dicha condición. Vid. Rudolf ENDRES, Adel und Patriziat in Oberdeutschland, en Winfried SCHULZE (Ed.), Ständische Gesellschaft und soziale Mobilität, Oldenbourg Verlag, Múnich, 1988, pp. 235-7.

${ }^{141}$ Vid. Rudolf ENDRES, op. cit., pp. 222 y ss.

${ }^{142}$ Vid. Rudolf KIESSLING, Bürgerliche Gesellschaft und Kirche in Augsburg im Spätmittelalter, Augsburgo, 1971.

${ }^{143}$ Vid. H. LIEBERICH, Rittermässigkeit und bürgerliche Gleichheit. Anmerkungen zur gesellschaftlichen Stellung des Bürgers im Mittelalter, en "Festschrift für Hermann Krause", Colonia-Viena, 1975, pp. 84-5 y 88.
} 
impuestos y exigiendo de ellos prestaciones de carácter militar ${ }^{144}$. Y de ahí que, ante estas exigencias, y por otros motivos, muchos de ellos optasen por renunciar a su pertenencia a la sociedad política urbana, para pasar a residir a sus señoríos rurales e integrarse en las corporaciones de nobleza de la región donde éstos se ubicaban ${ }^{145}$. Todo lo contrario ocurrió en la Corona de Castilla, donde, como hemos indicado, fueron muchos los señores de vasallos que vivieron en ciudades y desempeñaron en ellas oficios de gobierno, sin que por ello experimentase merma alguna su capacidad de ejercer plena autoridad en sus señoríos, desde los que incluso pusieron en práctica políticas que atentaban contra los intereses de la comunidad política urbana a la que ellos mismos servían como oficiales.

\section{LA NOBLEZA URBANA EN EL REINO DE FRANCIA}

Al igual que en el Imperio alemán, en el reino de Francia las sociedades políticas urbanas se mostraron remisas a admitir a miembros de la nobleza en su seno, y a reconocerles el derecho a desempeñar oficios relevantes en las instituciones de gobierno local. En principio la pertenencia a la nobleza no se consideraba compatible con la integración en el estamento ciudadano. Ciertamente se dieron casos de individuos que a título personal sí lograron hacer efectiva tal compatibilidad, como, por ejemplo, Jean Pizdou, prévôt des marchands de la ciudad de París, quien, cuando fue hecho noble por real privilegio, no renunció, sin embargo, al desempeño de este oficio de gobierno que denotaba una clara pertenencia al estamento ciudadano parisino $^{146}$. Pero casos como el suyo no fueron muy frecuentes, y, además, se ha de tener en cuenta que este individuo no era noble de sangre, sino que accedió a la nobleza por vía de privilegio. Y por ello su trayectoria no pone en cuestión la validez de la tesis de que la principal ciudad de Francia, París, excluyó a la nobleza de sus instituciones de gobierno, a pesar de que fueron numerosos los nobles, en muchos casos de elevadísimo rango, que tuvieron fijada allí su residencia, al menos durante algunos meses del año, ya desde los siglos bajomedievales.

Otras muchas ciudades siguieron en este punto el ejemplo de París, porque la nobleza del reino de Francia, muy en particular la de sangre, también llamada de capa y espada, se mostró muy reacia a admitir la incorporación en su seno de personas de origen ciudadano, sobre todo si no

\footnotetext{
${ }^{144}$ Más detalles al respecto, con referencias a los interesantes casos ilustrativos de
Nürnberg y Berna, en Máximo DIAGO HERNANDO, Los señoríos territoriales de las ciudades europeas bajomedievales. Análisis comparativo de los ejemplos castellano y alemán, "Hispania", 188 (1994), pp. 830-2.

${ }^{145}$ Vid. D. WILlOWEIT, Stadt und Territorium im Heiligen Römischen Reich. Eine Einführung, en G. CHITTOLINI y D. WILLOWEIT (Eds.), Statuten, Stâdte und Territorien zwischen Mittelalter und Neuzeit in Italien und Deutschland, Berlin, 1992, p. 46.

${ }^{146}$ Vid. R. CAZELLES, Nouvelle Histoire de Paris-Paris de la fin du règne de Philippe Auguste à la mort de Charles V. 1223-1380, Paris, 1972, p. 112.
} 
se mostraban dispuestas a romper todos los lazos que les unían con las sociedades política urbanas de las que procedían. Por ello, aunque durante los siglos bajomedievales fueron muchos los vecinos de distintas ciudades de Francia que compraron señoríos a nobles de capa y espada en dificultades financieras, éstos tropezaron con grandes dificultades para conseguir una plena equiparación con los miembros del estamento noble ${ }^{147}$, y en su mayor parte terminaron conformando un grupo social intermedio entre nobleza y burguesía $^{148}$. Y una suerte parecida corrieron los oficiales de aquellas ciudades francesas a los que los reyes concedieron el privilegio de nobleza a título colectivo, como es el caso, por ejemplo, de los escabinos de Poitiers, pues, si bien es cierto que se esforzaron por asimilarse a la nobleza de espada, nunca llegaron a ser reconocidos por ésta como iguales ${ }^{149}$.

Con carácter excepcional, no obstante, en algunas pocas ciudades francesas sí se ha podido constatar la presencia de nobles que estaban formalmente integrados en la sociedad política urbana, aunque en ningún caso ocupaban en su seno una posición de predominio, sino que por el contrario ejercían escasa influencia en el terreno político, y constituían más bien un grupo marginal. Es el caso, por ejemplo, de Dijon, donde según el profesor Dutour existió al menos desde el siglo XII una nobleza urbana constituida por "caballeros de castillo" ("milites castri"), que, no obstante, desaparecieron totalmente de escena hacia los años 1330-1350, por lo que en adelante los nobles residentes en esta ciudad pasaron a ser individuos que desarrollaban actividades propias de ciudadanos ${ }^{150}$. Según este autor se trataba de una nueva nobleza, constituida en un alto porcentaje por individuos ennoblecidos, que en bastantes casos se dedicaban a la práctica del comercio, y que por consiguiente distaron mucho de constituir un grupo bien definido en el seno de la sociedad política urbana, y reconocido como igual por la nobleza rural circundante. Por el contrario, para este autor, dichos nobles vecinos de Dijon, de los cuales llega a identificar a 59 entre los años 1350 y 1410, representaban más bien una variante dentro del grupo de los notables, y presentaban muy pocos puntos en común con la nobleza rural ${ }^{151}$.

También en la ciudad de Reims el profesor Desportes constató la presencia de algunos nobles en las primeras décadas del siglo XIII, pero los

\footnotetext{
${ }^{147} \mathrm{La}$ adquisición por burgueses de bienes pertenecientes a nobles, que comportaban el ejercicio de jurisdicción y la prestación de obligaciones feudales, fue autorizada formalmente por Felipe el Hermoso a partir de 1298. Pero como éstos, al no ser nobles, no podían jurídicamente realizar las prestaciones feudales quedaron obligados a pagar una compensación llamada "droit de franc fief". Philippe WOLFF, La noblesse toulousaine: essai sur son histoire médiévale, en Philippe CONTAMINE (Ed.), La noblesse au Moyen Age. XIe-XVe. siècles, "Essais à la mémoire de Robert Boutruche", Paris, PUF, 1976, p. 170.

${ }^{148}$ Vid. Gisela NAEGLE, Stadt, Recht und Krone. Französische Städte, Königtum und Parlement im späten Mittealter, Matthiesen Verlag, Husum, 2002, p. 241.

${ }^{149}$ Ibíd., pp. 223 y 341. Los escabinos de Poitiers como colectivo recibieron el privilegio de nobleza en 1372 .

${ }^{150}$ Thierry DUTOUR, La noblesse dijonnaise dans la seconde moitié du XIVe. Siècle (vers 1350-vers 14I0, en Commerce, Finances et Société (XIe-XVIe. Siècles). "Recueil de travaux d'histoire médiévale offert à M. le Professeur Henri Dubois", Sorbonne, París, 1993, p. 311.

${ }^{151}$ Ibíd., pp. 312-5.
} 
presenta como casos aislados, destacando por el contrario que en aquella época los nobles se habían convertido en figuras en gran medida extrañas a la vida urbana. Y hasta el punto esto era así que muchas familias se habían escindido en dos ramas, una noble y otra burguesa, al tiempo que eran muchos los gentilhombres que se desprendían de las casas que poseían en la ciudad, si bien este distanciamiento no impidió que se continuasen celebrando matrimonios mixtos entre nobles y burgueses, que, no obstante, a partir de 1270 se hicieron cada vez más raros ${ }^{152}$.

En el entorno de Reims también se ha constatado la existencia de una nobleza urbana en la ciudad de Châlons-sur-Marne ${ }^{153}$. En el Languedoc, por su parte, cabe destacar la ciudad de Tarascon donde, según Hébert, tanto nobles como burgueses tuvieron acceso a la principal institución de gobierno local $^{154}$. Y, por lo que respecta a Provenza, que se integró muy tardíamente en el reino de Francia, habiendo formado parte en origen del Imperio, también se ha constatado la presencia de nobles entre los miembros de la sociedad política local de Arles ${ }^{155}$.

A estos ejemplos cabe añadir los de otras ciudades en las que residieron individuos que en los siglos XIV y XV adquirieron la condición noble por privilegios que les fueron concedidos por los reyes a título individual o colectivo, como los hubo, por ejemplo, en Toulouse, según nos recuerda Philippe Wolf ${ }^{156}$. En conjunto, no obstante, la nobleza en Francia se definió como un estamento esencialmente rural, mientras que en las ciudades representó un grupo marginal desde el punto de vista sociopolítico. Las sociedades políticas urbanas en este reino tuvieron, en efecto, por el contrario, un marcado carácter "burgués" o "ciudadano", es decir, estuvieron constituidas por individuos que poseían un común status jurídico, entre los cuales predominaban los que tenían como principal dedicación el comercio, los oficios artesanales o las profesiones liberales. Pero incluso en aquellas ciudades en que está constatada la presencia de nobles formalmente integrados en la comunidad política local, éstos no tuvieron reconocido ningún régimen privilegiado de acceso al ejercicio del poder local, a diferencia de lo que ocurrió en las principales ciudades de la Corona de Castilla. Y cuando constatamos que hubo oficios que quedaron efectivamente reservados para los miembros del estamento noble, podemos comprobar que no se trató de oficios ordinarios, contemplados en el organigrama de autogobierno local, sino de oficios de carácter extraordinario de nombramiento regio. Es el caso en

${ }^{152}$ Pierre DesPortes, Reims et les Rémois aux XIII et XIV siècles, Picard, París, 1979, pp. 150-3, y 289.

${ }^{153}$ G. Clause y J. RavauX, Histoire de Châlons-sur-Marne, Roanne, 1983, p. 105.

${ }^{154} \mathrm{M}$. HÉBERT, La ville de Tarascon à la fin du XIV Siècle vers $1370-1400$. Tesis de tercer ciclo, Universidad de Provenza. 1975.

${ }^{155}$ Vid. Louis STOufF, Arles à la fin du Moyen Âge, 2 vols. Aix-en-Provence-Lille, 1986. Y Nobles et bourgeois dans l'Arles du bas Moyen Age: un patriciat? en Histoire et société, "Mélanges offerts à Georges Duby". Volume II: Le tenancier, le fidèle et le citoyen, Aix-enProvence, 1992, pp. 181-193.

${ }^{156}$ Philippe WOLFF, La noblesse toulousaine, cit. pp. 173-4. Según este autor los ennoblecimientos por el rey de vecinos de Toulouse se iniciaron en 1322 . 
concreto de los capitanes que fueron nombrados en muchas ciudades francesas por los reyes con carácter extraordinario en 1317, y de nuevo en 1358-9, para que estuviesen en ellas al frente de las tareas de defensa, todos los cuales fueron reclutados en el seno de la nobleza caballeresca, la llamada "de espada"157.

\section{EL CASO DE INGLATERRA}

Mucho menos presente todavía que en las ciudades francesas estuvo el elemento noble en las del reino de Inglaterra. Los nobles ingleses, tanto los magnates como los miembros de la gentry, mostraron una evidente inclinación por la vida en el campo, aunque, por supuesto, muchos de ellos llegaron a poseer casas en ciudades, muy en particular en Londres, en las que residían durante temporadas más o menos largas, que alternaban con las estancias en sus castillos y mansiones rurales. Pero ni siquiera estos nobles con residencias urbanas, y que pasaban largas temporadas en las mismas, llegaron a ser formalmente admitidos en las comunidades políticas urbanas, sobre las que a lo sumo pudieron ejercer influencia por procedimientos que actuaban al margen de las instituciones.

Los grupos dominantes de las principales ciudades inglesas, con Londres a la cabeza, estuvieron constituidos fundamentalmente por mercaderes $^{158}$. Y en este mismo grupo se reclutaron la mayor parte de los procuradores que representaron a estas ciudades en los Comunes, donde confluyeron con los miembros de la gentry que representaban en dicha asamblea a los condados. De hecho esta presencia regular en las asambleas de los Comunes no fue el único factor que contribuyó a acercar a las familias de las oligarquías mercantiles urbanas y las de la baja nobleza rural, o gentry. Según se ha podido constatar en varias monografías centradas en el análisis de casos regionales, los mercaderes más prósperos de determinadas ciudades tendieron a equipararse en su posición social con las familias de la nobleza rural de su entorno, hasta el punto de conseguir concertar alianzas matrimoniales con ellas, aunque no todas les aceptaban como iguales ${ }^{159}$. Algunos autores han apuntado incluso que durante el siglo $\mathrm{XV}$ tuvo lugar un proceso de "gentrification", es decir, de nobilización o, si se quiere, de asunción de pautas de comportamiento propias de la gentry, en las oligarquías urbanas de muchas ciudades inglesas. Pero en ningún caso dicho proceso desembocó en una plena equiparación de las familias integradas en dichas oligarquías y las de la gentry, por mucho que se concertasen de forma esporádica alianzas matrimoniales entre ellas. Más bien el acercamiento entre ambos grupos

${ }^{157}$ Vid. Gisela NAEGLE, op. cit., p. 143.

${ }^{158}$ Vid. R.H. HILTON, English and French towns in feudal society. A comparative study, Cambridge, Cambridge Úniversity Press 1992, p 100. Y Edward MILLER y John HATCHER, Medieval English Towns, Commerce and Crafts. 1086-1348, Longman, Londres-Nueva York, 1995 , pp. 347 y ss.

${ }^{159}$ Jenny KERMODE, Medieval Merchants. York, Berkeley and Hull in the Later Middle Ages, Cambridge University Press, 1998, p. 16. 
propició que, a veces, determinadas acaudaladas familias de procedencia urbana pudiesen abandonar su ciudad de residencia para incorporarse a la gentry de su entorno rural, como ha constatado Maryanne Kowaleski que ocurrió de forma ocasional en la ciudad de Exeter ${ }^{160}$.

La persistencia de una élite mercantil al frente de las ciudades inglesas a lo largo de todo el período bajomedieval ha sido destacada por Rodney Hilton como uno de los rasgos que más contribuye a diferenciar el paisaje sociopolítico urbano en Inglaterra con respecto al de Francia, país en el que, como hemos visto, tampoco alcanzó un importante desarrollo la nobleza urbana, pero en el que los mercaderes no lograron mantener una posición preeminente en sus ciudades de residencia, en las que el grupo dominante tendió a estar constituido de forma preferente, sobre todo a partir del siglo $\mathrm{XV}$, por oficiales al servicio del rey, que tendían a imitar las formas de vida de la nobleza ${ }^{161}$.

Esta tendencia a la imitación de la nobleza en las prácticas sociales también hizo progresos entre los mercaderes ingleses en el transcurso del siglo $\mathrm{XV}$, pero no lo suficiente como para que éstos dejasen de conceder absoluta prioridad a sus intereses mercantiles. Y, por consiguiente, las oligarquías urbanas inglesas mantuvieron entonces un marcado perfil burgués, que no sólo ofrece un importante contraste con el de sus homólogas de las ciudades francesas, como insiste en demostrar el profesor Hilton, sino también, y en muy mayor medida, con el de sus homólogas de las ciudades castellanas, de fuerte impronta nobiliaria. De modo que en cada uno de los tres principales territorios de Europa Occidental en los que durante el período bajomedieval se consolidaron fuertes estados monárquicos centralizados -Castilla, Inglaterra y Francia- las estructuras sociopolíticas urbanas evolucionaron conforme a modelos muy dispares.

\footnotetext{
${ }^{160}$ Maryanne KowALESKI, Local markets and regional trade in medieval Exeter,Cambridge, Cambridge University Press, 1995, p. 114.

${ }^{161}$ Rodney HiLton, op. cit., pp. 103-4.
} 